\title{
A Real-Time Evaporation Correction Scheme for Radar-Derived Mosaicked Precipitation Estimations
}

\author{
STEVEN M. MARTINAITIS \\ Cooperative Institute for Mesoscale Meteorological Studies, University of Oklahoma, and NOAA/OAR/National Severe Storms \\ Laboratory, Norman, Oklahoma \\ HEATHER M. GRAMS \\ NOAA/NWS/Radar Operations Center, Norman, Oklahoma \\ CARRIE LANGSTON \\ Cooperative Institute for Mesoscale Meteorological Studies, University of Oklahoma, and NOAA/OAR/National Severe Storms \\ Laboratory, Norman, Oklahoma \\ JIAN ZHANG AND KENNETH HOWARD \\ NOAA/OAR/National Severe Storms Laboratory, Norman, Oklahoma
}

(Manuscript received 23 May 2017, in final form 7 September 2017)

\begin{abstract}
Precipitation values estimated by radar are assumed to be the amount of precipitation that occurred at the surface, yet this notion is inaccurate. Numerous atmospheric and microphysical processes can alter the precipitation rate between the radar beam elevation and the surface. One such process is evaporation. This study determines the applicability of integrating an evaporation correction scheme for real-time radar-derived mosaicked precipitation rates to reduce quantitative precipitation estimate (QPE) overestimation and to reduce the coverage of false surface precipitation. An evaporation technique previously developed for largescale numerical modeling is applied to Multi-Radar Multi-Sensor (MRMS) precipitation rates through the use of 2D and 3D numerical weather prediction (NWP) atmospheric parameters as well as basic radar properties. Hourly accumulated QPE with evaporation adjustment compared against gauge observations saw an average reduction of the overestimation bias by $57 \%-76 \%$ for rain events and $42 \%-49 \%$ for primarily snow events. The removal of false surface precipitation also reduced the number of hourly gauge observations that were considered as "false zero" observations by $52.1 \%$ for rain and $38.2 \%$ for snow. Optimum computational efficiency was achieved through the use of simplified equations and hourly 10-km horizontal resolution NWP data. The run time for the evaporation correction algorithm is 6-7 s.
\end{abstract}

\section{Introduction}

High spatiotemporal resolution surface precipitation values are vital to multiple hydrometeorological applications, including flood prediction and water resource management. Other applications, such as providing realtime information related to wildfire suppression, require knowing whether precipitation is even occurring at the surface. Precipitation gauge measurements can provide real-time surface accumulations, but gauge networks

\footnotetext{
Corresponding author: Steven M. Martinaitis, steven.martinaitis@ noaa.gov
}

lack the spatial distribution needed to accurately represent precipitation, especially with convection (e.g., Goodrich et al. 1995). Radar-derived quantitative precipitation estimation (QPE) provides better spatial coverage and resolution than precipitation gauges. Radar-based QPE is determined at beam level and occurs at varying altitudes above the ground; therefore, it is important to understand that radar-derived precipitation rates and accumulations do not necessarily equate to the actual precipitation measured at the surface.

Microphysical and environmental processes can alter precipitation rates between the elevated radar beam level and the surface. A primary contributor to these 
differences is evaporation. Analyses of radar observations describe the depletion of small hydrometeors and the evolution of the drop size distribution (DSD) of precipitation through evaporation (Levin et al. 1991; Penide et al. 2013). Neglecting evaporative effects has been shown to create significant uncertainties in surface rainfall retrievals (Comstock et al. 2004) and a subsequent overestimation of surface rain rates (Gori and Joss 1980; Hu and Srivastava 1995; Li and Srivastava 2001); thus, the need exists for a real-time evaporative correction of radar-derived precipitation rates.

Radar observations have been used to indirectly estimate evaporation through fixed relationships between reflectivity $Z$ and either rainwater content lost (Leary and Houze 1979) or rainfall rates (Rosenfeld and Mintz 1988); however, Li and Srivastava (2001) noted that utilizing fixed relationships resulted in significant errors with estimating evaporation and precipitation rates. Numerous studies examined changes in polarimetric variables to modify precipitation in models through microphysical parameterizations. $\mathrm{Li}$ and Srivastava (2001) evaluated a single raindrop using $Z$ and differential reflectivity $Z_{\mathrm{DR}}$ to modify the DSD and rain rate through evaporation in a steady-state thermodynamic environmental profile. Kumjian and Ryzhkov (2010) investigated the vertical changes of polarimetric variables and its impacts on liquid precipitation rates < $10 \mathrm{~mm} \mathrm{~h}^{-1}$ within a one-dimensional rainshaft model. Xie et al. (2016) also examined the vertical change in $Z$ and $Z_{\mathrm{DR}}$ with respect to evaporation, evaporationrelated cooling rates below the melting layer, and DSD evolution through validation of DSD observations and microphysical simulations with radar observations indicating evaporation.

The inclusion of polarimetric variables resulted in improved evaporative correction of precipitation and mitigated uncertainties in surface-based QPE; however, some limitations with utilizing polarimetric datasets exist. Challenges arise when approximating changes in $Z_{\mathrm{DR}}$ values for solid precipitation sampled above the melting layer that transition to liquid precipitation prior to reaching the surface. Polarimetric fields like $Z_{\mathrm{DR}}$ can be noisy and require proper calibration. Furthermore, an evaporation correction scheme based on polarimetric data would also preclude its use in areas covered by radars without dual-polarization technology.

Other model parameterizing of evaporation defined the evaporation coefficient to be dependent upon precipitation rates but treated the evaporation of rain and snow as the same (Schlesinger et al. 1988; Sundqvist 1988; Feingold 1993). Microphysical modeling techniques have identified evaporative differences between rain and snow (e.g., Clough and Franks 1991), and
Heymsfield and Donner (1990) suggested a separate evaporation parameterization of snow, since snow was shown to evaporate faster than rain. Gregory (1995) derived an evaporation correction methodology applicable for both rain and snow precipitation rates in large-scale numerical models through a number of simplifications and assumptions regarding microphysical properties. The results were comparable to previous studies using more complex evaporative calculations (e.g., Clough and Franks 1991) and various DSDs; moreover, the simplifications were designed for increased computational efficiency to run within a largescale modeling framework.

This paper discusses the applicability of implementation of an evaporation correction scheme for real-time mosaicked radar-based precipitation rate fields within the high spatiotemporal resolution Multi-Radar MultiSensor (MRMS) system (Zhang et al. 2016). The evaporation correction scheme was designed around the work of Gregory (1995) and applied to the 3D MRMS grid space through a computationally efficient methodology. The objectives of applying an evaporation correction algorithm to radar-derived precipitation are to reduce the overestimation of QPE in environments defined by subsaturated atmospheric profiles, remove false surface precipitation (i.e., precipitation detected at the radar beam level but not occurring at the surface), and improve the quality control (QC) of automated hourly gauge observations. The computing time of the evaporative correction scheme is also evaluated to ensure it has minimal impact on real-time data latency within the operational MRMS system.

\section{Evaporation correction equations}

The fundamental theory of evaporation for a water droplet or ice particle is generally framed as the rate of mass diffusion with respect to time (e.g., Rogers and Yau 1996; Li and Srivastava 2001; Kumjian and Ryzhkov 2010),

$$
\frac{d m}{d t}=2 \pi D f_{v} D_{v}(T, p)\left[\rho_{v}-\rho_{v s}\left(T_{w}\right)\right],
$$

where $m$ is the mass of a water droplet or ice particle with diameter $D, f_{v}$ is the ventilation coefficient for vapor diffusivity, $D_{v}$ is the molecular diffusion coefficient, $\rho_{v}$ is the vapor density of the ambient environment, and $\rho_{v s}$ is the saturation vapor density, which is the equivalent of the vapor density at the water droplet or ice particle surface. The quantity $\rho_{v}-\rho_{v s}$ is the vapor density deficit as a function of wet-bulb (or ice bulb) temperature $T_{w}$ of the air through which the hydrometeor falls. The direct use of Eq. (1) is computationally inefficient for real-time use. 
TABLE 1 . The seven different precipitation types classified for the MRMS SPT product. Listed are the $R-Z$ relationship, the reflectivity cap $(\mathrm{dBZ})$, and rate cap $\left(\mathrm{mm} \mathrm{h}^{-1}\right)$ for each precipitation type.

\begin{tabular}{llcr}
\hline \hline MRMS SPT classification & $R-Z$ relationship & Reflectivity cap $(\mathrm{dB} Z)$ & Rate cap $\left.(\mathrm{mm} \mathrm{h})^{-1}\right)$ \\
\hline Cool stratiform rain & $R=0.0365 Z^{0.625}$ & 50 & 48.6 \\
Warm stratiform rain & $R=0.1155 Z^{0.5}$ & 50 & 48.6 \\
Tropical stratiform rain & $R=0.010 Z^{0.833}$ & 50 & 103.8 \\
Convective rain & $R=0.017 Z^{0.714}$ & 53 & 103.8 \\
Tropical convective rain & $R=0.010 Z^{0.833}$ & 50 & 103.8 \\
Hail & $R=0.017 Z^{0.714}$ & 49 & 53.8 \\
Snow & $R=0.1155 Z^{0.5}$ & - & - \\
\hline
\end{tabular}

Evaporation would have to be considered over the entire spectrum of drop sizes and changes in DSD. The quantity $T_{w}$ can only be calculated through an iterative method and not analytically. The mass of precipitation present would also have to be converted to fit relevant radar outputs (e.g., precipitation rates).

Gregory (1995) provided a simplified methodology of evaporating precipitation for both rain and snow through the use of precipitation rates and atmospheric characteristics only. The first simplification was removing the iterative calculations of defining $T_{w}$ at temperature $T$ and mixing ratio $q$. Kinzer and Gunn (1951) provided an estimation of

$$
D_{v}(T, p)\left[\rho_{v}-\rho_{v s}\left(T_{w}\right)\right]
$$

for water droplets as a function of $T$ and relative humidity $U$ at a pressure $p$ of $1000 \mathrm{hPa}$. It is assumed that the temperature of the water droplet is equal to the ventilated wet-bulb temperature. A similar estimation for ice was derived using the diffusivity of water vapor over ice from List (1951) and ventilated ice bulb temperatures estimated via hydrologic tables from U.K. Meteorological Office (1964). Gregory (1995) stated that it would be more computationally efficient to derive the vapor density deficit in terms of $T$ by calculating Eq. (2) at various values of $T$ and $U$ and fitting a quadratic equation to the results. Equation (2) can then be expressed as

$$
A_{v}(T, p)\left[\rho_{v}-\rho_{v s}(T)\right],
$$

where $A_{v}(T, p)$ has differing coefficients for rain,

$$
\begin{aligned}
A_{v}^{w}(T, p)= & \left(2.008 \times 10^{-9} T^{2}-1.385 \times 10^{-6} T\right. \\
& \left.+2.424 \times 10^{-4}\right)\left(10^{5} / p\right),
\end{aligned}
$$

and for snow,

$$
\begin{aligned}
A_{v}^{s}(T, p)= & \left(-5.2 \times 10^{-9} T^{2}+2.5332 \times 10^{-6} T\right. \\
& \left.-2.9111 \times 10^{-4}\right)\left(10^{5} / p\right) .
\end{aligned}
$$

Another simplification was deriving evaporation as a change in precipitation rate instead of mass diffusion. When accounting for the entire spectrum of drop sizes $N(D)$ and the substitution of Eq. (2) with Eq. (3), Eq. (1) is rewritten as

$$
\frac{d M}{d t}=\beta\left[\rho_{v}-\rho_{v s}(T)\right],
$$

where $M$ is the total mass of precipitation and $\beta$ is the bulk evaporation coefficient defined as

$$
\beta=2 \pi A_{v}(T, p) \int_{0}^{\infty} D f_{v}(D) N(D) d D .
$$

The precipitation rate $P$ can be defined as

$$
P=V M,
$$

where $V$ is the mass-weighted fall speed over the droplet spectrum that can be approximated as

$$
V=A M^{a} .
$$

This resulted in an evaporation correction scheme based on the change of the precipitation rate with respect to height $z$,

$$
\frac{d P}{d z}=(1+a) \frac{d M}{d t}=(1+a) \beta\left[\rho_{v}-\rho_{v s}(T)\right],
$$

where $a$ is the exponent variable from Eq. (9). The estimated mass-weighted fall speeds yielded values of $a=0.20$ for rain and $a=0.17$ for snow.

The evaporation correction scheme was further simplified by approximating $\beta$ using assumed properties for hydrometeor fall speeds, ventilation coefficients, and fixed DSDs, while ensuring the results best matched the findings from Clough and Franks (1991). Parameter $\beta$ for rain was defined as

$\beta=A_{v}^{w}(T, p)\left[122.68\left(P \rho^{0.5}\right)^{0.52}+919.25 \rho^{0.59} P^{0.67}\right]$,

based on a gamma DSD empirically determined by Ulbrich (1983). Parameter $\beta$ for snow was defined as 
TABLE 2. List of 2D and 3D RAP model output fields utilized in the MRMS evaporation correction scheme, the units of each model output field, and the input fields and/or unit conversions for each output.

\begin{tabular}{|c|c|c|c|}
\hline Dimensions & Model output fields & Units & Input fields or conversions \\
\hline \multirow[t]{4}{*}{$2 \mathrm{D}$} & Surface temperature $\left(T_{\mathrm{sfc}}\right)$ & ${ }^{\circ} \mathrm{C}$ & Converted from $\mathrm{K}$ to ${ }^{\circ} \mathrm{C}$ \\
\hline & Surface wet-bulb temperature $\left(T_{w}\right)$ & ${ }^{\circ} \mathrm{C}$ & $\begin{array}{l}\text { Derived from surface temperature, surface dewpoint temperature, and } \\
\text { surface pressure; converted from } \mathrm{K} \text { to }{ }^{\circ} \mathrm{C}\end{array}$ \\
\hline & Freezing level height $\left(z_{\mathrm{fz}}\right)$ & $\mathrm{m}$ AGL & Converted from MSL to AGL using RAP model surface height field \\
\hline & Surface height $\left(z_{\mathrm{sfc}}\right)$ & m AGL & (For converting MRMS 3D grid heights from MSL to AGL) \\
\hline \multirow[t]{4}{*}{$3 \mathrm{D}$} & Temperature $(T)$ & $\mathrm{K}$ & Converted from $\mathrm{K}$ to ${ }^{\circ} \mathrm{C}$ \\
\hline & Pressure $(p)$ & $\mathrm{Pa}$ & Derived from pressure level lookup table \\
\hline & Density $(\rho)$ & $\mathrm{kg} \mathrm{m}^{-3}$ & Derived from $3 \mathrm{D}$ pressure and $3 \mathrm{D}$ temperature \\
\hline & Vapor density deficit $\left[\rho_{v}-\rho_{v s}(T)\right]$ & $\mathrm{kg} \mathrm{m}^{-3}$ & Derived from 3D pressure, 3D temperature, and 3D relative humidity $U$ \\
\hline
\end{tabular}

$$
\beta=A_{v}^{s}(T, p)\left[1765.55\left(P \rho^{0.5}\right)^{0.55}+34784.06 \rho^{0.63} P^{0.76}\right]
$$

based on a Marshall-Palmer DSD (Marshall and Palmer 1948).

The density of air $\rho$ used in $\beta$ is derived from the ideal gas law,

$$
\rho=\frac{p m}{R T},
$$

where $R$ is the gas constant $\left(8.3144598 \mathrm{~m}^{3} \mathrm{~Pa} \mathrm{~mol}^{-1} \mathrm{~K}^{-1}\right)$ and $m$ is the mean molar mass of dry air $\left(28.9645 \mathrm{~g} \mathrm{~mol}^{-1}\right)$. The vapor density deficit function $\left(\rho_{v}-\rho_{v s}\right)$ in Eq. (10) is based on the approximation of $\rho_{v s}$ using Eq. (13), where $m$ is now the molar mass of water $\left(18.01528 \mathrm{~g} \mathrm{~mol}^{-1}\right)$. The quantity $\rho_{v}$ is then defined as

$$
\rho_{v}=\rho_{v s} \times U
$$

where $U$ is the relative humidity. For a complete discussion and full derivation of the equations, see Gregory (1995).

\section{Methodology for applying real-time evaporation}

\section{a. Radar QPE accumulations}

The QPE utilized in this study is from the fully automated MRMS system (Zhang et al. 2016). A primary output from the MRMS system is a real-time radar-only QPE provided at a spatial resolution of approximately $1 \mathrm{~km} \times 1 \mathrm{~km}$ with a temporal resolution of $2 \mathrm{~min}$. The radar-only QPE is derived from a seamless mosaic of overlapping quality-controlled 3D radar data from across the continental United States (CONUS) and southern Canada. Each individual WSR-88D 3D volume scan undergoes a dual-polarization radar quality control to remove nonmeteorological echoes (Tang et al. 2014) while the Canadian radar network uses a mostly reflectivity-based QC structure (Zhang et al. 2016). Other algorithms are employed to remove the influences of beam blockage and nonmeteorological features (e.g., wind farms) through power compensation assuming standard beam propagation, cross-azimuth interpolation, and utilizing higher radar elevation angles in the creation of a single-radar seamless hybrid scan reflectivity (SHSR; Zhang et al. 2016). The use of an apparent vertical profile of reflectivity with the single-radar SHSR fields allows for the correction of reflectivity values in the brightband region where the radar beam intersects the melting layer (Zhang and Qi 2010; Zhang et al. 2012a; Qi et al. 2013a,b).

The single-radar SHSR fields are mosaicked together using a weighting variable that favors lower altitude data and allows for a smooth blending of radar reflectivity values between neighboring radars (Zhang et al. 2016). Some false precipitation removal is conducted during the mosaicking process by setting a grid cell to

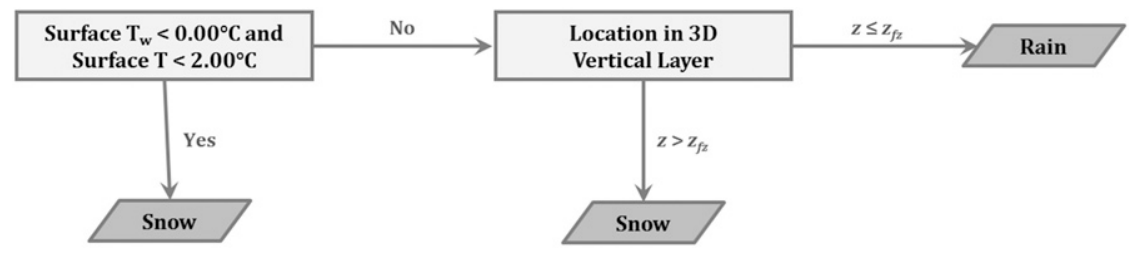

FIG. 1. Logic for defining the 3D precipitation type of each grid cell. Surface logic is based on the MRMS SPT algorithm (Zhang et al. 2016). Logic throughout the 3D vertical layer based on location at each height $z$ with respect to the freezing level height $z_{\mathrm{fz}}$. 


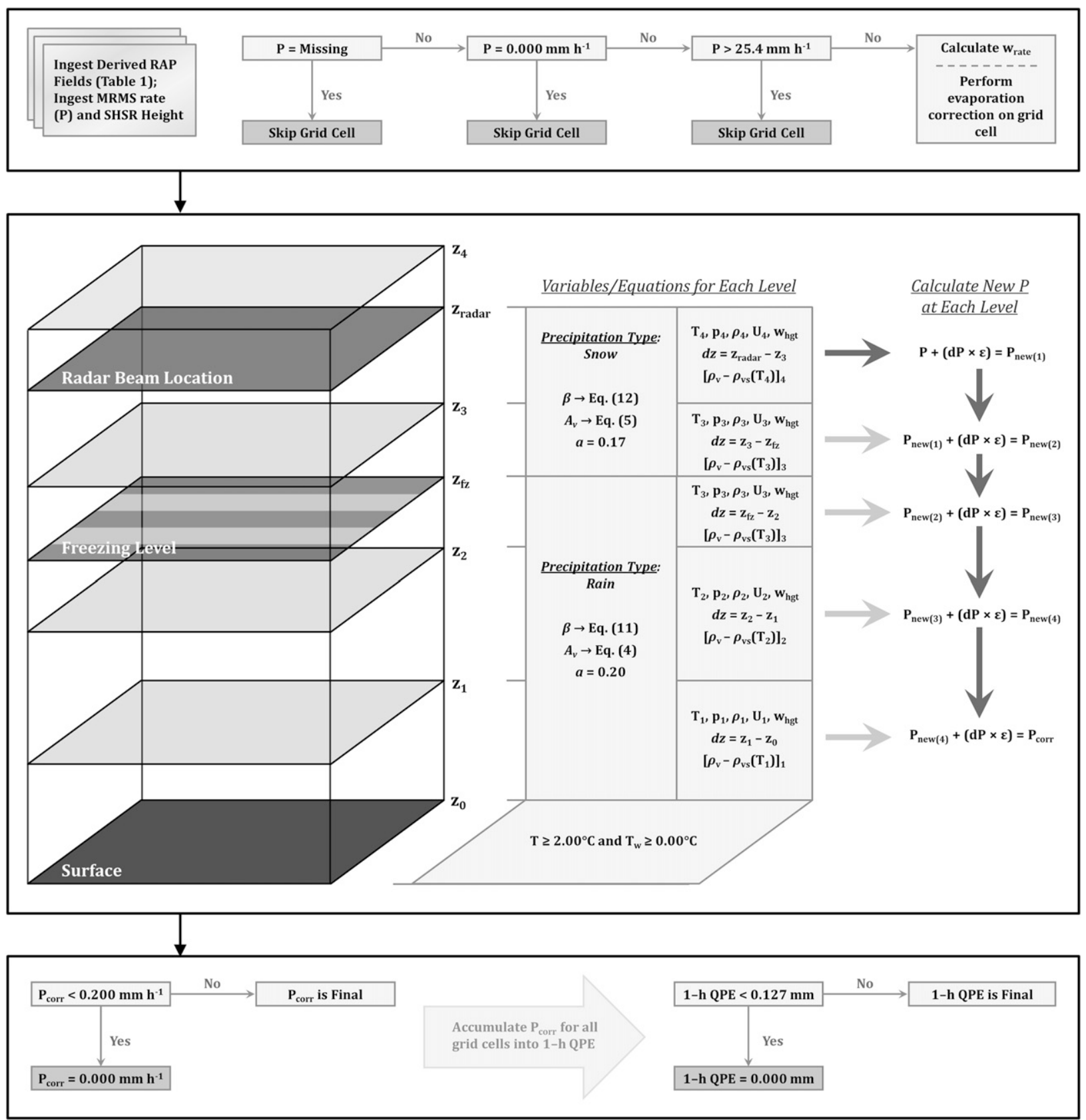

FIG. 2. Diagram of evaporation correction scheme with example calculation for $P_{\text {corr }}$ at a grid point where both precipitation types occur within the vertical layer. The lowest available instantaneous precipitation rate data based on the radar beam location at height $z_{\text {radar }}$ is located above the freezing level $z_{\mathrm{fz}}$. The surface precipitation type is classified as rain in this diagram.

no reflectivity if precipitation is not found at the lowest altitude radar bin among multiple radars covering the same grid cell (Qi and Zhang 2017). This was designed to mitigate virga; however, at farther ranges from a radar site, the lowest available datum could sample the precipitation aloft and not the lack of precipitation near the surface. The final mosaicked SHSR field is then used to generate the precipitation rates within MRMS.

Radar reflectivity properties and environmental data created by the Rapid Refresh (RAP) model (Benjamin et al. 2016) are utilized to generate a surface precipitation type (SPT) product in MRMS (Zhang et al. 2016). There are seven different precipitation classifications within 
TABLE 3. List of the eight events evaluated in MRMS using the evaporation correction scheme. Provided in this table are the event number, the start and end dates/times for the events, the total hours evaluated for each event, and the domain area for each event as defined by the northwest (NW) and southeast (SE) corner latitudes and longitudes. The asterisk by the number of total hours for event 6 denotes that $1 \mathrm{~h}$ of observations was missing for the QPE evaluations.

\begin{tabular}{|c|c|c|c|c|c|}
\hline \multirow[b]{2}{*}{ Event No. } & \multicolumn{2}{|c|}{ Event date/time } & \multirow[b]{2}{*}{ Total hours } & \multicolumn{2}{|c|}{ Domain area } \\
\hline & Start & End & & NW corner & SE corner \\
\hline 1 & 0500 UTC 20 Sep 2016 & 0800 UTC 21 Sep 2016 & 28 & $39.0^{\circ} \mathrm{N}, 119.5^{\circ} \mathrm{W}$ & $31.0^{\circ} \mathrm{N}, 103.5^{\circ} \mathrm{W}$ \\
\hline 2 & 0500 UTC 20 Sep 2016 & 2300 UTC 21 Sep 2016 & 43 & $50.0^{\circ} \mathrm{N}, 116.0^{\circ} \mathrm{W}$ & $44.0^{\circ} \mathrm{N}, 96.0^{\circ} \mathrm{W}$ \\
\hline 3 & 0100 UTC 2 Nov 2016 & 1000 UTC 3 Nov 2016 & 34 & $49.0^{\circ} \mathrm{N}, 125.0^{\circ} \mathrm{W}$ & $43.0^{\circ} \mathrm{N}, 116.0^{\circ} \mathrm{W}$ \\
\hline 4 & 0900 UTC 7 Nov 2016 & 2100 UTC 8 Nov 2016 & 37 & $40.0^{\circ} \mathrm{N}, 95.0^{\circ} \mathrm{W}$ & $29.0^{\circ} \mathrm{N}, 85.0^{\circ} \mathrm{W}$ \\
\hline 5 & 0100 UTC 3 Dec 2016 & 0400 UTC 4 Dec 2016 & 28 & $39.0^{\circ} \mathrm{N}, 94.0^{\circ} \mathrm{W}$ & $30.0^{\circ} \mathrm{N}, 81.0^{\circ} \mathrm{W}$ \\
\hline 6 & 0100 UTC 11 Dec 2016 & 0100 UTC 12 Dec 2016 & $21^{*}$ & $46.0^{\circ} \mathrm{N}, 87.0^{\circ} \mathrm{W}$ & $38.0^{\circ} \mathrm{N}, 72.0^{\circ} \mathrm{W}$ \\
\hline 7 & 1000 UTC 30 Jan 2017 & 1000 UTC 1 Feb 2017 & 49 & $49.0^{\circ} \mathrm{N}, 98.0^{\circ} \mathrm{W}$ & $38.0^{\circ} \mathrm{N}, 78.0^{\circ} \mathrm{W}$ \\
\hline 8 & 0200 UTC 18 Feb 2017 & 1100 UTC 19 Feb 2017 & 34 & $40.0^{\circ} \mathrm{N}, 92.5^{\circ} \mathrm{W}$ & $29.5^{\circ} \mathrm{N}, 77.0^{\circ} \mathrm{W}$ \\
\hline
\end{tabular}

MRMS, and each grid cell can be assigned its own ratereflectivity $(R-Z)$ relationship based on the precipitation type classified in the SPT product (Table 1). The tropical $R-Z$ relationship is blended with the convective and warm stratiform $R-Z$ relationships based on a weighting function dependent upon probability of warm rain (POWR; Grams et al. 2014) field. Application of the tropical $R-Z$ relationship is also dependent upon the longitudinal location of the grid cell within the domain. Derived precipitation rates are then accumulated to create the radaronly QPE for varying temporal periods. A full description of how the precipitation rates and QPEs are generated in MRMS can be found in Zhang et al. (2016).

\section{b. Real-time system implementation}

Two algorithms are developed to implement the evaporation correction equations derived by Gregory (1995) to function within the real-time MRMS system. The first algorithm creates hourly environmental profiles from the RAP model. The RAP model has a $13-\mathrm{km}$ horizontal resolution and 37 vertical pressure levels at 25-hPa intervals from 1000 to $100 \mathrm{hPa}$. Model-based outputs and select evaporation correction variables (Table 2) are placed into binary arrays and remapped onto the MRMS 3D grid space. This is the first instance of 3D model data being utilized in the MRMS system. The horizontal grid spacing uses a 10-km Cartesian grid. The vertical grid spacing of MRMS has a $250-\mathrm{m}$ resolution from 500 to $3000 \mathrm{~m}$ above mean sea level (MSL), a 500-m resolution from 3000 to $9000 \mathrm{~m}$ MSL, and a 1000-m resolution from 9000 to $19000 \mathrm{~m}$ MSL. The 3D RAP model data were restricted in the vertical to $12000 \mathrm{~m}$ MSL for computational efficiency. The surface elevation field utilized by the RAP model is subtracted from the native MRMS vertical grid spacing to change the MRMS 3D grid heights from MSL to above ground level (AGL). This is important to consider when comparing the RAP model fields to the height of the radar data.
The second algorithm applies the evaporation correction equations and derived hourly RAP model fields to the 2-min resolution MRMS radar-only precipitation rates. This algorithm is designed to identify and correct only the $1 \mathrm{~km} \times 1 \mathrm{~km}$ MRMS grid cells containing a nonmissing, nonzero precipitation rate values $P$ in rain/snow regimes only. This allows the algorithm to bypass an average of $97 \%-$ $98 \%$ of all grid cells in the MRMS CONUS domain. Two weighting variables are also implemented to limit the application of evaporation and improve computational efficiency. The first limiting application of the scheme is a weighting variable based upon the initial $P$ derived by radar $\left(w_{\text {rate }}\right)$. It is intended to reduce the evaporation correction at MRMS grid points where $P>12.7 \mathrm{~mm} \mathrm{~h}^{-1}\left(0.50 \mathrm{in} . \mathrm{h}^{-1}\right)$ and bypass grid points where $P \geq 25.4 \mathrm{~mm} \mathrm{~h}^{-1}\left(1.00 \mathrm{in.} \mathrm{h}^{-1}\right)$. The quantity $w_{\text {rate }}$ is defined as

$w_{\text {rate }}=\left\{\begin{array}{cc}P \leq 12.7 ; & 1 \\ 12.7<P \leq 25.4 ; & (25.4-P) / 12.7 \\ P>25.4 ; & 0\end{array}\right.$

Kumjian and Ryzhkov (2010) noted that the effects of evaporation on $P>10 \mathrm{~mm} \mathrm{~h}^{-1}$ become less significant versus other microphysical processes, such as coalescence and breakup. The threshold $P$ of $12.7 \mathrm{~mm} \mathrm{~h}^{-1}$ was employed to make the correction scheme more aggressive per conceptual tests of the algorithm within the MRMS framework.

The second limiting application is a weighting variable based on the height AGL ( $\left.w_{\text {hgt }}\right)$. It is intended to reduce the application of evaporation for vertical layers below the radar beam height $z_{\text {radar }}$ that exceed $2000 \mathrm{~m}$ AGL and is defined as

$w_{\text {hgt }}=\left\{\begin{array}{cc}z_{n} \leq 2000 ; & 1 \\ 2000<z_{n} \leq 3000 ; & {\left[\left(3000-z_{n}\right)\right] / 1000} \\ z_{n}>3000 ; & 0\end{array}\right.$ 
TABLE 4. Designation of each gauge QC flag for hourly gauge observations, including precipitation type that each flag is dependent upon, the gauge $G$ vs radar $R$ comparison logic, and whether the observation is retained for use in the MRMS system. Modified from Qi et al. (2016).

\begin{tabular}{llccc}
\hline \hline QC flag & QC flag designation & Precipitation type & Gauge-radar comparison & Retained for use \\
\hline-2 & Outside time window & - & - & No \\
-1 & Unchecked & - & $G, R=0$ & Yes \\
0 & Pass & Both & $G, R>0 ; G \approx R$ & Yes \\
0 A & Pass (nonzero) & Both & $G=0, R>0$ & Yes \\
1 & False zero & Rain & $G>0, R=0$ & No \\
2 & False precipitation & Both & $G, R>0 ; G \gg R$ & No \\
$3 \mathrm{R}$ & Outlier high & Rain & $G, R>0 ; G \gg R$ & No \\
$3 \mathrm{~S}$ & Outlier high & Snow & $G, R>0 ; G \ll R$ & No \\
4 & Outlier low & Rain & $G=0, R>0$ & No \\
5 & Frozen impacts & Snow & $G, R>0 ; G \ll R$ & No \\
$5 \mathrm{~A}$ & Frozen impacts (nonzero) & Snow & No & \\
6 & Suspect value & Both & & \\
\hline
\end{tabular}

where $z_{n}$ is the height of the top of each vertical layer in the MRMS 3D grid profile. Vertical MRMS levels with $z_{n} \geq 3000 \mathrm{~m}$ AGL are bypassed in the correction scheme. This was designed to specifically augment the precipitation below the cloud base under the assumption that the cloud based is generally less than $2000 \mathrm{~m}$ AGL. The two weighting variables are combined into a single weighting function $\varepsilon$ to use within downward vertical calculations through each MRMS 3D grid point, and it is defined as

$$
\varepsilon=w_{\text {rate }} \times w_{\text {hgt }}
$$

The delineation of rain and snow at the surface uses a simplified version of the MRMS SPT algorithm from Zhang et al. (2016), while a simple decision tree determines the 3D precipitation profile of each grid cell (Fig. 1). The precipitation type is classified as snow for the entire vertical profile if the surface model $T_{\text {sfc }}<$ $2.00^{\circ} \mathrm{C}$ and $T_{w}<0.00^{\circ} \mathrm{C}$. If the surface model $T_{\text {sfc }} \geq$ $2.00^{\circ} \mathrm{C}$ or $T_{w} \geq 0.00^{\circ} \mathrm{C}$, then the precipitation is classified as rain below the freezing level $z_{\mathrm{fz}}$ and snow above $z_{\mathrm{fz}}$. Identifying the $3 \mathrm{D}$ precipitation types then dictates the value of $a$ utilized in Eq. (9) and the equations for $A_{v}$ and $\beta$ depending on the classification of rain [Eqs. (4) and (11)] and snow [Eqs. (5) and (12)] at each vertical level.

The final corrected precipitation rate $P_{\text {corr }}$ is calculated for each grid cell through a downward calculation from the radar beam level to the surface (Fig. 2). The model-based environmental variables at each $3 \mathrm{D}$ vertical layer are defined for the top of each vertical level $z_{n}$. An intermediate precipitation rate $P_{\text {new }(n)}$ is calculated for each downward vertical layer until reaching the surface. A vertical layer containing the $z_{\mathrm{fz}}$ would utilize separate calculations for snow above $z_{\mathrm{fz}}$ and rain below $z_{\mathrm{fz}}$ (e.g., Fig. 2). The minimum precipitation rate generated in the MRMS system is $0.200 \mathrm{~mm} \mathrm{~h}^{-1}\left(0.0079 \mathrm{in.}^{-1}\right)$; thus, values of $P_{\text {corr }}<0.200 \mathrm{~mm} \mathrm{~h}^{-1}$ are set to $0.00 \mathrm{~mm} \mathrm{~h}^{-1}$. The minimum hourly accumulated QPE value generated in the MRMS system is $0.127 \mathrm{~mm}(0.005 \mathrm{in}$.); thus, new hourly accumulated QPEs $<0.127 \mathrm{~mm}$ based on $P_{\text {corr }}$ are set to $0.00 \mathrm{~mm}$.

\section{c. Timing of algorithms}

The time needed to generate the MRMS radar-based precipitation rates and QPEs over the MRMS CONUS domain before evaporation correction can be up to $90 \mathrm{~s}$.

TABLE 5. Classification of the primary precipitation type, the gauge precipitation total, the MRMS radar-only precipitation total, and the bias percentage between the rain and gauge accumulations for each case study.

\begin{tabular}{cccrr}
\hline \hline Event No. & Precipitation type & Gauge total $(\mathrm{mm})$ & MRMS QPE $(\mathrm{mm})$ & Bias $(\%)$ \\
\hline 1 & Rain & 1155.77 & 1822.20 & +57.7 \\
2 & Rain & 567.80 & 1142.60 & +101.2 \\
3 & Rain & 1319.92 & 1707.20 & +29.3 \\
4 & Rain & 4008.11 & 5496.90 & +37.1 \\
5 & Rain & 6689.83 & 12246.50 & +83.1 \\
6 & Snow & 754.38 & 3084.90 & +308.9 \\
7 & Snow & 952.98 & 4013.00 & +321.1 \\
8 & Rain & 2909.56 & 5940.50 & +104.2 \\
\hline
\end{tabular}


TABLE 6. Comparison of the ME and MAE of the MRMS radar-only QPE before and after evaporation correction for the six rain events and the average value for these rain events. Listed are the values based on gauge vs radar comparisons, the differences in values when applying the evaporation correction scheme, and the percent change in values. Accumulations of the radar and gauge precipitation data used in the comparisons are based on values at gauge sites designated as passing for nonzero values and false zero values.

\begin{tabular}{|c|c|c|c|c|c|c|c|c|}
\hline \multirow[b]{2}{*}{ Event No. } & \multicolumn{2}{|c|}{ Pre-evaporation } & \multicolumn{2}{|c|}{ Postevaporation } & \multicolumn{2}{|c|}{ Difference } & \multicolumn{2}{|c|}{ Percent change } \\
\hline & $\mathrm{ME}(\mathrm{mm})$ & $\operatorname{MAE}(\mathrm{mm})$ & $\operatorname{ME}(\mathrm{mm})$ & MAE $(\mathrm{mm})$ & $\mathrm{ME}(\mathrm{mm})$ & MAE (mm) & ME & MAE \\
\hline 1 & 0.353 & 0.443 & 0.085 & 0.215 & -0.268 & -0.228 & -76.0 & -51.5 \\
\hline 2 & 0.392 & 0.436 & 0.117 & 0.204 & -0.275 & -0.232 & -70.3 & -53.2 \\
\hline 3 & 0.231 & 0.344 & 0.071 & 0.212 & -0.160 & -0.132 & -69.4 & -38.4 \\
\hline 4 & 0.276 & 0.374 & 0.119 & 0.237 & -0.157 & -0.137 & -57.1 & -36.6 \\
\hline 5 & 0.548 & 0.628 & 0.198 & 0.305 & -0.350 & -0.323 & -63.8 & -51.4 \\
\hline 8 & 0.397 & 0.428 & 0.137 & 0.183 & -0.260 & -0.245 & -65.5 & -57.2 \\
\hline Avg & 0.426 & 0.486 & 0.150 & 0.242 & -0.276 & -0.244 & -64.8 & -50.2 \\
\hline
\end{tabular}

Given the 120-s temporal resolution for these products, the calculation period for an evaporative correction scheme must be minimized to contribute very little additional latency. The algorithm generating and translating the RAP model data onto the MRMS 3D grid space is designed to run separately from any radar-based code and to run only at the top of each hour. The eight 2D and 3D RAP model-derived fields (Table 2) generated in a $10-\mathrm{km}$ horizontal resolution are completed in approximately $12 \mathrm{~s}$. The algorithm applying the evaporation correction equations to the original MRMS radaronly precipitation rates is designed to run prior to the QPE accumulation algorithm. Ingesting the modelderived data into the evaporation correction algorithm requires $2 \mathrm{~s}$, and the evaporation correction calculations require $4-5 \mathrm{~s}$; therefore, the overall run time and additional latency to generate the corrected rate product is approximately 6-7 s.

The greatest contributor to the fast computation time is the use of remapped 3D RAP data at the coarser 10-km horizontal resolution. Employing 1-km horizontal resolution RAP model data to match the native MRMS grid spacing would have increased the generation of the model-derived fields for each hour to approximately 750-850 s; moreover, the ingest of these higher-resolution model fields into the evaporation correction algorithm was $52-54 \mathrm{~s}$, which would extend the latency of the evaporation corrected precipitation rate product beyond the 2-min temporal resolution.

\section{d. Case study analysis}

Evaluations of the evaporation correction scheme were conducted on eight different cases with a sample size totaling $274 \mathrm{~h}$ (Table 3 ). Archived RAP model data were obtained from the National Centers for Environmental Prediction (NCEP), and the initialization times of the RAP model data were utilized in the case studies. MRMS data were obtained from the National Severe Storms Laboratory (NSSL). Rain was the principal precipitation type for events $1-5$ and 8 , whereas events 6 and 7 were predominantly snow in wind fields that were generally less than $6 \mathrm{~m} \mathrm{~s}^{-1}$ to ensure adequate catch efficiency of the gauges (Rasmussen et al. 2012). There exist well documented challenges regarding automated hourly precipitation gauges measuring the accumulated water content of frozen precipitation, such as blockage of the gauge orifice, that presented a limited dataset of nonzero gauge observations (e.g., Rasmussen et al. 2012; Martinaitis et al. 2015); however, it is important to consider how evaporation impacts snowfall events and the subsequent gauge QC within the MRMS system.

The MRMS gauge QC algorithm used to evaluate the automated hourly gauges and the radar QPE

TABLE 7. As in Table 6, but for FB and CC.

\begin{tabular}{|c|c|c|c|c|c|c|c|c|}
\hline \multirow[b]{2}{*}{ Event No. } & \multicolumn{2}{|c|}{ Pre-evaporation } & \multicolumn{2}{|c|}{ Postevaporation } & \multicolumn{2}{|c|}{ Difference } & \multicolumn{2}{|c|}{ Percent change } \\
\hline & FB & $\mathrm{CC}$ & FB & $\mathrm{CC}$ & FB & $\mathrm{CC}$ & FB & $\mathrm{CC}$ \\
\hline 1 & -0.448 & 0.861 & -0.129 & 0.918 & +0.319 & +0.057 & 71.2 & 6.6 \\
\hline 2 & -0.672 & 0.671 & -0.262 & 0.796 & +0.410 & +0.125 & 61.0 & 18.6 \\
\hline 3 & -0.251 & 0.923 & -0.090 & 0.951 & +0.161 & +0.028 & 64.1 & 3.0 \\
\hline 4 & -0.313 & 0.944 & -0.148 & 0.961 & +0.165 & +0.017 & 52.7 & 1.8 \\
\hline 5 & -0.597 & 0.898 & -0.261 & 0.929 & +0.336 & +0.031 & 56.3 & 3.5 \\
\hline 8 & -0.656 & 0.848 & -0.294 & 0.916 & +0.362 & +0.068 & 55.2 & 8.0 \\
\hline Avg & -0.519 & 0.902 & -0.220 & 0.938 & +0.299 & +0.036 & 57.6 & 4.0 \\
\hline
\end{tabular}


TABLE 8. As in Table 6, but for the two snow events. Accumulations of the radar and gauge precipitation data used in the comparisons are based on values at gauge site classified as passing for nonzero values, false zeroes, and frozen impacts.

\begin{tabular}{|c|c|c|c|c|c|c|c|c|}
\hline \multirow[b]{2}{*}{ Event No. } & \multicolumn{2}{|c|}{ Pre-evaporation } & \multicolumn{2}{|c|}{ Postevaporation } & \multicolumn{2}{|c|}{ Difference } & \multicolumn{2}{|c|}{ Percent change } \\
\hline & $\mathrm{ME}(\mathrm{mm})$ & $\operatorname{MAE}(\mathrm{mm})$ & $\mathrm{ME}(\mathrm{mm})$ & $\operatorname{MAE}(\mathrm{mm})$ & $\mathrm{ME}(\mathrm{mm})$ & $\operatorname{MAE}(\mathrm{mm})$ & $\mathrm{ME}$ & MAE \\
\hline 6 & 0.313 & 0.344 & 0.160 & 0.201 & -0.153 & -0.143 & -48.9 & -41.6 \\
\hline 7 & 0.307 & 0.335 & 0.176 & 0.215 & -0.131 & -0.120 & -42.6 & -35.8 \\
\hline Avg & 0.311 & 0.339 & 0.170 & 0.209 & -0.141 & -0.130 & -45.5 & -38.3 \\
\hline
\end{tabular}

product performance through gauge $G$ versus radar $R$ comparisons was modified from Qi et al. (2016). Martinaitis et al. (2015) quantified the impacts of frozen precipitation on a CONUS-scale collection of automated precipitation gauge networks and demonstrated how impacted gauge observations can improperly bias a local gauge correction scheme for radar-derived QPE. This work prompted the removal of all nonzero hourly gauge observations in the QC methodology; however, the MRMS gauge QC algorithm was updated to allow for nonzero hourly gauge observations by setting an outlier winter maximum threshold $\mathrm{WR}_{\max }$ and minimum threshold $\mathrm{WR}_{\min }$ using the following equations:

$$
\begin{aligned}
& \mathrm{WR}_{\text {max }}=R \times[3.03-(0.3 \times R)] \quad \text { and } \\
& \mathrm{WR}_{\text {min }}=0.8 \times R .
\end{aligned}
$$

The quantities $\mathrm{WR}_{\max }$ and $\mathrm{WR}_{\min }$ were subjectively derived from approximately $90000 G-R$ pairings in winter precipitation environments where $G, R>0$. Similar gauge QC flags modified from Qi et al. (2016) were applied based on $G-R$ comparisons and precipitation type (Table 4). QC flag $=0$ (pass) was separated based on whether both $G, R$ were zero or both were nonzero and within the maximum and minimum outlier thresholds. The QC flag $=3$ (outlier high) was separated based on rain and snow, since different equations were applied to determine the maximum outlier thresholds. QC flag $=5$ (frozen impacts) was also separated based on whether the gauge value was zero or nonzero but below $\mathrm{WR}_{\min }$. All gauge observations $G>6.35 \mathrm{~mm}$ ( $0.25 \mathrm{in}$.) in a winter precipitation environment were designated with a QC flag $=6$ (suspect value) to remove erroneous gauge observations considered beyond hourly record snowfall liquid equivalent accumulations likely due to a technical malfunction or communication reporting issue.

Performance evaluations of the evaporation correction scheme were conducted for each event using the number of radar-gauge pairs $N$ based on the classification of gauge observations from the QC algorithm. The $N$ for rain events utilized gauge observations designated as passing for nonzero values and false zero values. The $N$ for snow events also includes gauge observations classified as frozen impacts. The initial performance of the MRMS radar-only QPE versus gauge observations showed a QPE overestimation ranging from 29\% to $104 \%$ for the six rain events (Table 5). The two snow events had apparent QPE overestimation of $>300 \%$ when comparing the radar to gauge accumulations (Table 5); however, the true overestimation is unknown given the potential adverse impacts on gauge instrumentation from frozen precipitation.

Statistical metrics used to evaluate the MRMS radaronly QPE included the mean error (ME), mean absolute error (MAE), fractional bias (FB), and correlation coefficient (CC) of the radar-derived QPE before and after evaporation correction with respect to gauges, which are defined as

$$
\begin{aligned}
\mathrm{ME} & =\bar{R}-\bar{G}, \\
\mathrm{MAE} & =\overline{|R-G|}, \quad \text { and } \\
\mathrm{FB} & =2 \times\left(\frac{\bar{G}-\bar{R}}{\bar{G}+\bar{R}}\right) .
\end{aligned}
$$

\begin{tabular}{|c|c|c|c|c|c|c|c|c|}
\hline \multirow[b]{2}{*}{ Event No. } & \multicolumn{2}{|c|}{ Pre-evaporation } & \multicolumn{2}{|c|}{ Postevaporation } & \multicolumn{2}{|c|}{ Difference } & \multicolumn{2}{|c|}{ Percent Change } \\
\hline & FB & $\mathrm{CC}$ & $\mathrm{FB}$ & $\mathrm{CC}$ & FB & $\mathrm{CC}$ & FB & $\overline{\mathrm{CC}}$ \\
\hline 6 & -1.219 & 0.520 & -0.886 & 0.573 & +0.333 & +0.053 & 27.3 & 10.2 \\
\hline 7 & -1.232 & 0.375 & -0.958 & 0.460 & +0.274 & +0.085 & 22.2 & 22.7 \\
\hline Avg & -1.226 & 0.442 & -0.927 & 0.512 & +0.299 & +0.070 & 24.4 & 15.8 \\
\hline
\end{tabular}

Ideal values for ME, MAE, and FB are 0.00. The ideal value for $\mathrm{CC}$ is 1.00 . Acceptable performance values for $\mathrm{FB}$ are $-0.5 \leq \mathrm{FB} \leq+0.5$. Detailed hourly assessments

TABLE 9. As in Table 7, but for the two snow events. 
TABLE 10. The change in the number of gauge observations classified as false zero observations before and after evaporation correction for each rain event. Listed are the difference in the total number of observations per event, the difference change per hour, and the percent change in the number of false zero observations.

\begin{tabular}{|c|c|c|c|c|c|}
\hline Event No. & $\begin{array}{c}\text { Before evaporation } \\
\text { correction }\end{array}$ & $\begin{array}{c}\text { After evaporation } \\
\text { correction }\end{array}$ & $\begin{array}{c}\text { Difference with } \\
\text { evaporation }\end{array}$ & $\begin{array}{l}\text { Difference change } \\
\text { per hour }\end{array}$ & $\begin{array}{l}\text { Percent } \\
\text { change }\end{array}$ \\
\hline 1 & 935 & 388 & -547 & $-19.5 h^{-1}$ & -58.5 \\
\hline 2 & 748 & 311 & -437 & $-10.2 \mathrm{~h}^{-1}$ & -58.4 \\
\hline 3 & 553 & 300 & -253 & $-7.4 \mathrm{~h}^{-1}$ & -45.8 \\
\hline 4 & 1913 & 1176 & -737 & $-19.9 h^{-1}$ & -38.5 \\
\hline 5 & 4621 & 2242 & -2379 & $-85.0 \mathrm{~h}^{-1}$ & -51.5 \\
\hline 8 & 3975 & 1686 & -2289 & $-67.3 h^{-1}$ & -57.8 \\
\hline Avg & & & & $-32.6 h^{-1}$ & -52.1 \\
\hline
\end{tabular}

of events 1 and 7 also include an analysis of the mean bias ratio (MBR) of the radar-based QPE before and after evaporation correction for hours containing at least 10 gauge sites classified as passing with $G$ and $R>0$ :

$$
\operatorname{MBR}=\frac{\bar{R}}{\bar{G}} .
$$

An analysis of the number of observations that were retained or removed through the gauge QC algorithm both before and after evaporation correction were also examined. This was conducted in areas of adequate radar coverage using the MRMS Radar Quality Index (RQI) that derives the potential quality of the radar data based upon beam blockage, beamwidth, and beam sampling with respect to the freezing level (Zhang et al. $2012 \mathrm{~b}$ ). A threshold of RQI $\geq 0.1$ was applied in this study. Detailed hourly analyses of events 1 and 7 are presented in sections $4 \mathrm{~b}$ and $4 \mathrm{c}$, respectively.

\section{e. Limitations}

Multiple challenges and limitations must be acknowledged with the application and verification of the evaporation correction scheme as well as the datasets employed in this study. The DSDs that define $\beta$ for rain and snow are static, yet DSDs evolve during evaporation and alter the relationship between reflectivity and precipitation rates (e.g., Li and Srivastava 2001; Kumjian and Ryzhkov 2010). Limited $R-Z$ relationships are available within the MRMS system for rainfall, and only a single $R-Z$ relationship is utilized for the liquid equivalent of frozen precipitation (Zhang et al. 2016), which could also introduce errors in the treatment of evaporation. Changes in DSDs would also impact the collective hydrometeor fall speeds, which is also a static variable in the correction scheme. The scheme also does not account for evaporative changes within the melting layer, and it utilizes a sharp gradient between frozen precipitation and rain in the vertical profile. Model biases and shortcomings, such as imperfect model physics and initial conditions (Cui et al. 2012), can impact the environmental variables and the degree of evaporation applied to the precipitation rates.

There are multiple error sources when considering the use of radar-derived QPE to depict precipitation over a given region. Precipitation values estimated by radar are subject to contamination via ground clutter, nonmeteorological echoes, anomalous propagation, ducting, and beam blockage (e.g., Young et al. 1999; Harrison et al. 2000), while underrepresentation of QPE can occur by overshooting precipitation features at far distances (Smith et al. 1996; Steiner et al. 1999). Nonuniform beam filling and large sample sizes at farther distances from the radar might also provide nonrepresentative reflectivity data or create biases in present precipitation (Rogers 1971; Rosenfeld et al. 1992,

TABLE 11. As in Table 10, but for the number of gauge observations classified as passing for nonzero gauge values for each rain event.

\begin{tabular}{cccccc}
\hline \hline Event No. & $\begin{array}{c}\text { Before evaporation } \\
\text { correction }\end{array}$ & $\begin{array}{c}\text { After evaporation } \\
\text { correction }\end{array}$ & $\begin{array}{c}\text { Difference with } \\
\text { evaporation }\end{array}$ & $\begin{array}{c}\text { Change in observations } \\
\text { per hour }\end{array}$ & $\begin{array}{c}\text { Percent } \\
\text { change }\end{array}$ \\
\hline 1 & 978 & 965 & -13 & $-0.5 \mathrm{~h}^{-1}$ & -1.3 \\
2 & 727 & 696 & -31 & $-0.7 \mathrm{~h}^{-1}$ & -4.3 \\
3 & 1187 & 1164 & -23 & $-0.7 \mathrm{~h}^{-1}$ & -1.9 \\
4 & 3545 & 3510 & -35 & $-1.0 \mathrm{~h}^{-1}$ & -1.0 \\
5 & 5784 & 5715 & -69 & $-2.5 \mathrm{~h}^{-1}$ & -1.2 \\
8 & 3719 & 3688 & -31 & $-0.9 \mathrm{~h}^{-1}$ & -0.8 \\
Avg & & & & $-1.0 \mathrm{~h}^{-1}$ & -1.3 \\
\hline
\end{tabular}


TABLE 12. As in Table 10, but for the number of gauge observations defined by $G=0, R>0$ (false zero and frozen impacts) for each snow event.

\begin{tabular}{cccccc}
\hline \hline Event No. & $\begin{array}{c}\text { Before evaporation } \\
\text { correction }\end{array}$ & $\begin{array}{c}\text { After evaporation } \\
\text { correction }\end{array}$ & $\begin{array}{c}\text { Difference with } \\
\text { evaporation }\end{array}$ & $\begin{array}{c}\text { Change in observations } \\
\text { per hour }\end{array}$ & $\begin{array}{c}\text { Percent } \\
\text { change }\end{array}$ \\
\hline 6 & 6099 & 3687 & -2412 & $-100.5 \mathrm{~h}^{-1}$ & -39.5 \\
7 & 8093 & 5080 & -3013 & $-61.5 \mathrm{~h}^{-1}$ & -37.2 \\
Avg & & & & $-74.3 \mathrm{~h}^{-1}$ & -38.2 \\
\hline
\end{tabular}

1993). Improper calibration, erroneously high precipitation from melting layer effects, and limited operational $R-Z$ relationships can also impact radar-derived precipitation rates (e.g., Smith 1986; Smith et al. 1996; Young et al. 1999); however, these limitations are generally mitigated within the MRMS system (Zhang et al. 2016). Variations in the fall speeds of hydrometeors can also create a temporal difference between detection at the radar beam level and the surface (e.g., Kalogiros et al. 2014). This is especially true with the slow fall speeds of snowfall, which can introduce significant time delays between radar and surface detection (Thériault et al. 2012).

There are also limitations with the use of hourly precipitation gauge observations as a verification dataset. Rasmussen et al. (2012) and Martinaitis et al. (2015) provide a detailed catalog of sources of errors and limitations with automated precipitation gauges. The gauge QC methodology applied in this study helps delineate between quality observations and those potentially impacted by meteorological conditions or technical issues; however, the existence of radar-based false surface precipitation can mislabel an accurate $G=0.00 \mathrm{~mm}$ observation as incorrect.

Previous studies documented the numerous limitations that should be considered when conducting intercomparisons using radar-derived QPE estimated at beam-level and surface precipitation gauge observations (e.g., Wilson and Brandes 1979; Krajewski et al. 2010; Cocks et al. 2017). Bringi et al. (2011) documents error sources when comparing radar-based precipitation rates and estimates to gauge observations, including the representativeness of a point observation versus the areal resolution of a radar grid cell and point-to-area variances. The interpolation of the single-radar data in their native resolution onto the $1 \mathrm{~km} \times 1 \mathrm{~km}$ MRMS grid spacing must also be considered in the comparison process.

\section{Postevaporation QPE results}

\section{a. Overall statistics and analysis}

Application of the evaporation correction scheme reduced ME by an average of $64.8 \%$ across the six rain events, signifying a considerable overall mitigation of the overestimation bias (Table 6). The reduction in ME ranged between $57 \%$ and $76 \%$, and the three events with the greatest percent reduction in ME (events 1-3) occurred over the western half of the MRMS CONUS domain. The average ME values for all rain events after evaporation correction were under $0.200 \mathrm{~mm}$, and events 1 and 3 concluded with $\mathrm{ME}<0.100 \mathrm{~mm}$. The MAE also decreased by $50.2 \%$ from an average of 0.486 to $0.242 \mathrm{~mm}$. Statistical improvements were also noted in the FB and CC values for rain events (Table 7). The average FB value was improved by $57.6 \%$ to -0.220 , which is within range of acceptable performance for FB values. The average CC improved by a modest $4.0 \%$ from 0.902 to 0.938 . Five of the six rain events had a $\mathrm{CC}>0.910$, while the sixth event (event 2 ) had the greatest increase in CC.

The average ME and MAE values for the two snow events were reduced by an average of $45.5 \%$ and $38.3 \%$, respectively, after evaporation correction (Table 8 ). These reductions in ME and MAE were less than those with the rain events. The average ME value of $0.170 \mathrm{~mm}$ is comparable to the average ME value of $0.150 \mathrm{~mm}$ for the six rain events. Overall MAE values were lower due to smaller hourly liquid-equivalent accumulation values in snow versus rain events. FB values were far from the defined adequate performance range, and the $\mathrm{CC}$ values were considerably lower than rain events (Table 9); moreover, the percent improvement of FB values in snow events were a fraction of the improvement seen during the rain events. The average post-evaporation

TABLE 13. As in Table 11, but for each snow event

\begin{tabular}{cccccc}
\hline \hline Event No. & $\begin{array}{c}\text { Before evaporation } \\
\text { correction }\end{array}$ & $\begin{array}{c}\text { After evaporation } \\
\text { correction }\end{array}$ & $\begin{array}{c}\text { Difference with } \\
\text { evaporation }\end{array}$ & $\begin{array}{c}\text { Change in observations } \\
\text { per hour }\end{array}$ & $\begin{array}{c}\text { Percent } \\
\text { change }\end{array}$ \\
\hline 6 & 1148 & 1090 & -58 & $-2.4 \mathrm{~h}^{-1}$ & -5.1 \\
7 & 1851 & 1729 & -122 & $-2.5 \mathrm{~h}^{-1}$ & -6.6 \\
Avg & & & & $-2.5 \mathrm{~h}^{-1}$ & -6.0 \\
\hline
\end{tabular}




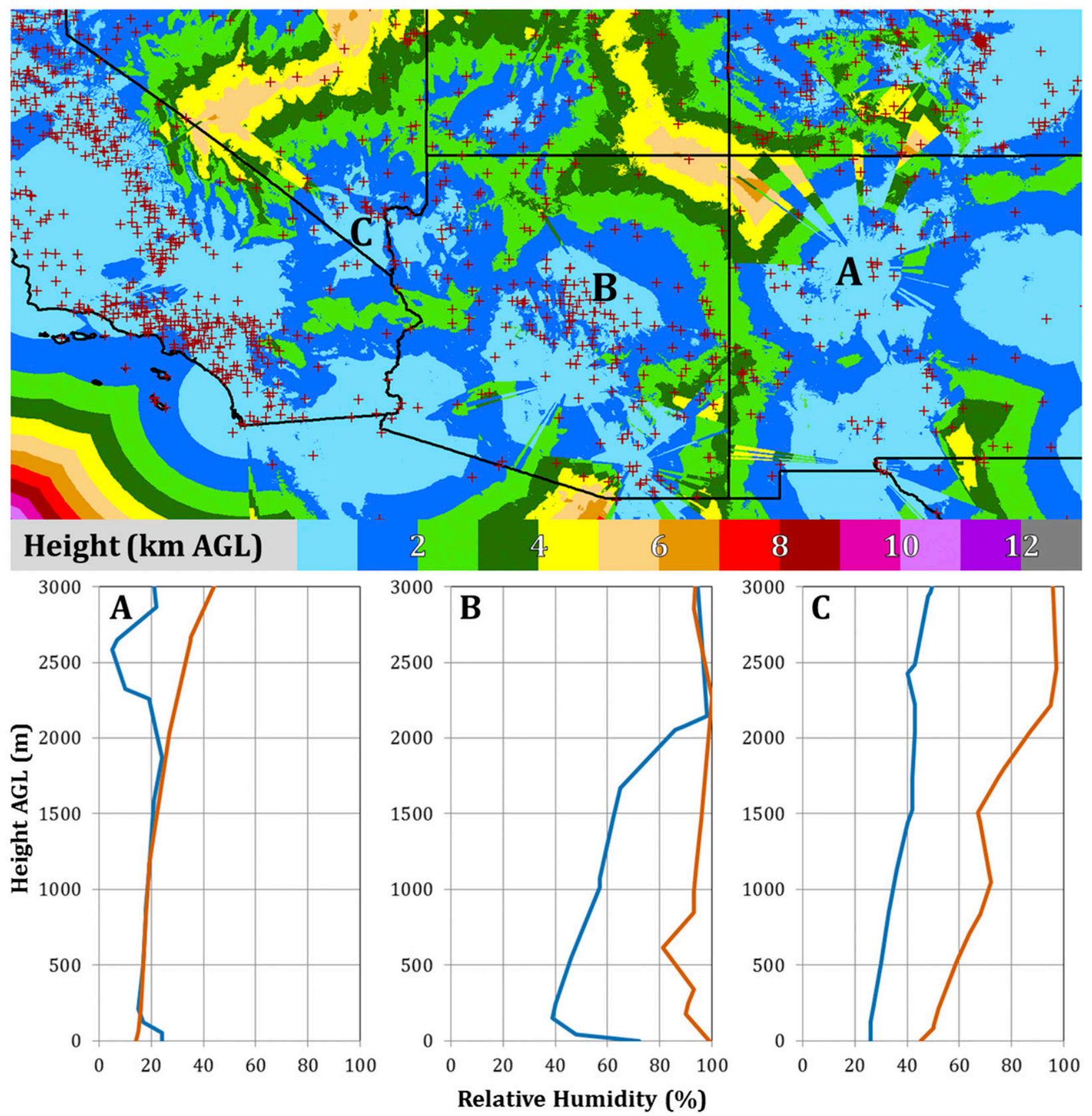

—1200 UTC 20 September 2016 —0000 UTC 21 September 2016

FIG. 3. Height of lowest available radar data from SHSR ( $\mathrm{km}$ AGL) and gauge locations (red + signs) for the domain of event 1 with observed relative humidity profiles for (a) Albuquerque, New Mexico; (b) Flagstaff, Arizona; and (c) Las Vegas, Nevada, at 1200 UTC 20 Sep 2016 (blue) and 0000 UTC 21 Sep 2016 (orange) to a height of $3000 \mathrm{~m}$ AGL.

correction value of $\mathrm{FB}$ was -0.927 , which was only a $24.4 \%$ improvement. The average $\mathrm{CC}$ improved by $15.8 \%$, but only to a value of 0.512 . These overall smaller improvements in the statistical measures can be attributed to the uncertainty in the quality of automated gauge observations in winter precipitation.
The resulting gauge QC prior to and after evaporation correction is characterized by a substantial change of nonpassing gauge-radar comparisons defined by false zero observations to passing gauge QC with $G, R=0$; moreover, there was a minimal decrease of passing nonzero gauge observations. The 


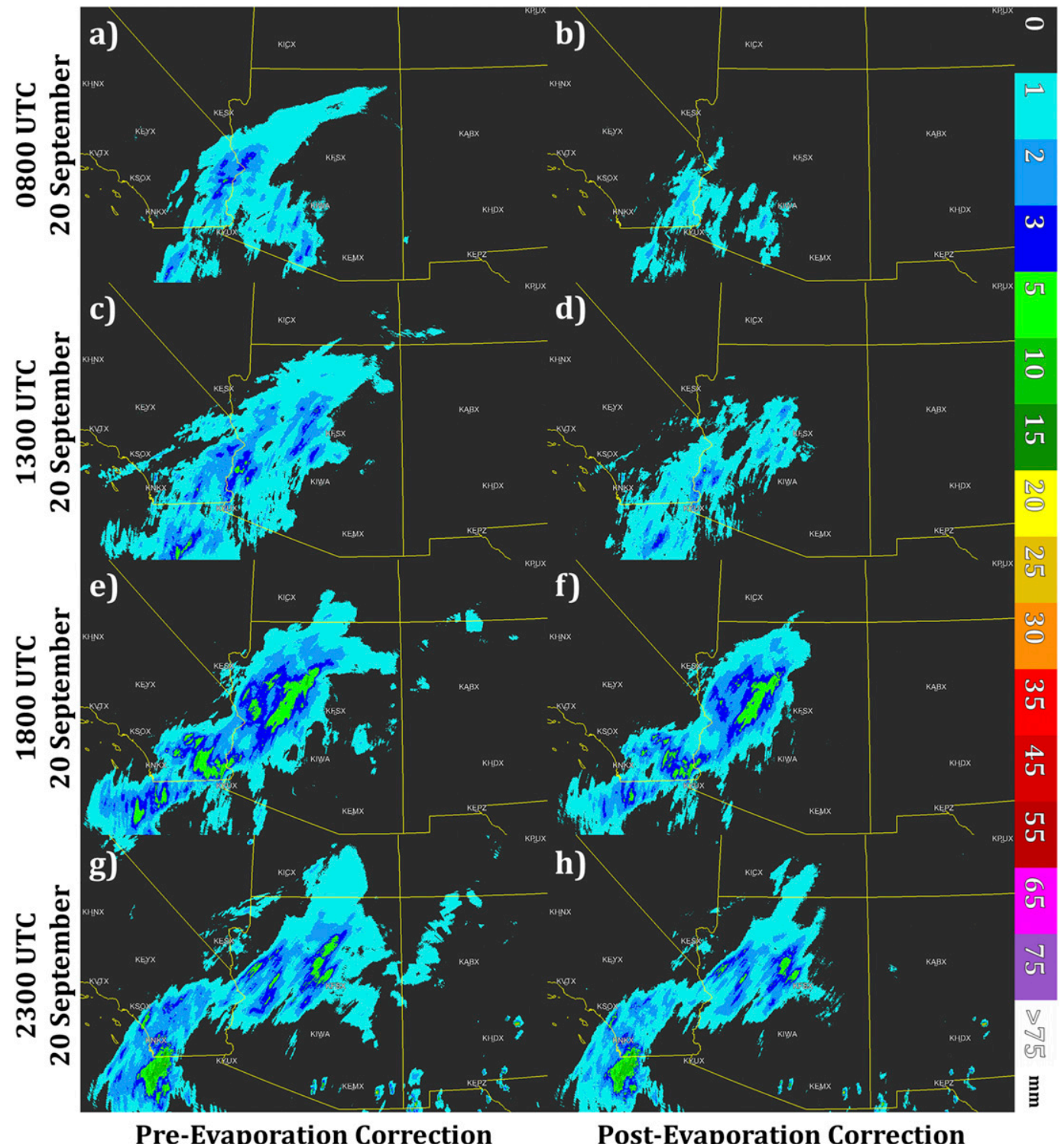

FIG. 4. Hourly MRMS radar-only QPE accumulations (left) before and (right) after evaporation correction during event 1 for the following times: (a),(b) 0800; (c),(d) 1300; (e),(f) 1800; and (g),(h) 2300 UTC 20 Sep.

number of gauge observations marked as false zero during the six rain events was reduced by $52.1 \%$ (Table 10). In contrast, approximately $1.3 \%$ of passing nonzero gauge observations was classified as nonpassing after evaporation correction (Table 11). This was an average of $0.5-2.5$ gauge observations per hour depending on gauge coverage density for each event.

The application of evaporation to snowfall events reduced the gauge observations defined by $G=0$, $R>0$ (either as false zero or frozen impacts) by $38.2 \%$ (Table 12). The percent change is smaller compared to rain events; however, it is unknown if the gauges originally classified by frozen impacts were based on precipitation being detected aloft not reaching the surface or unmeasured snowfall accumulations due to gauge instrumentation limitations. Approximately $6.0 \%$ of passing nonzero gauge observations were classified as nonpassing after applying the evaporation correction scheme (Table 13). This implies that the evaporation scheme is more aggressive in removing snowfall that reached the surface; however, some nonzero gauge observations could be the result of thawing winter precipitation coinciding with 


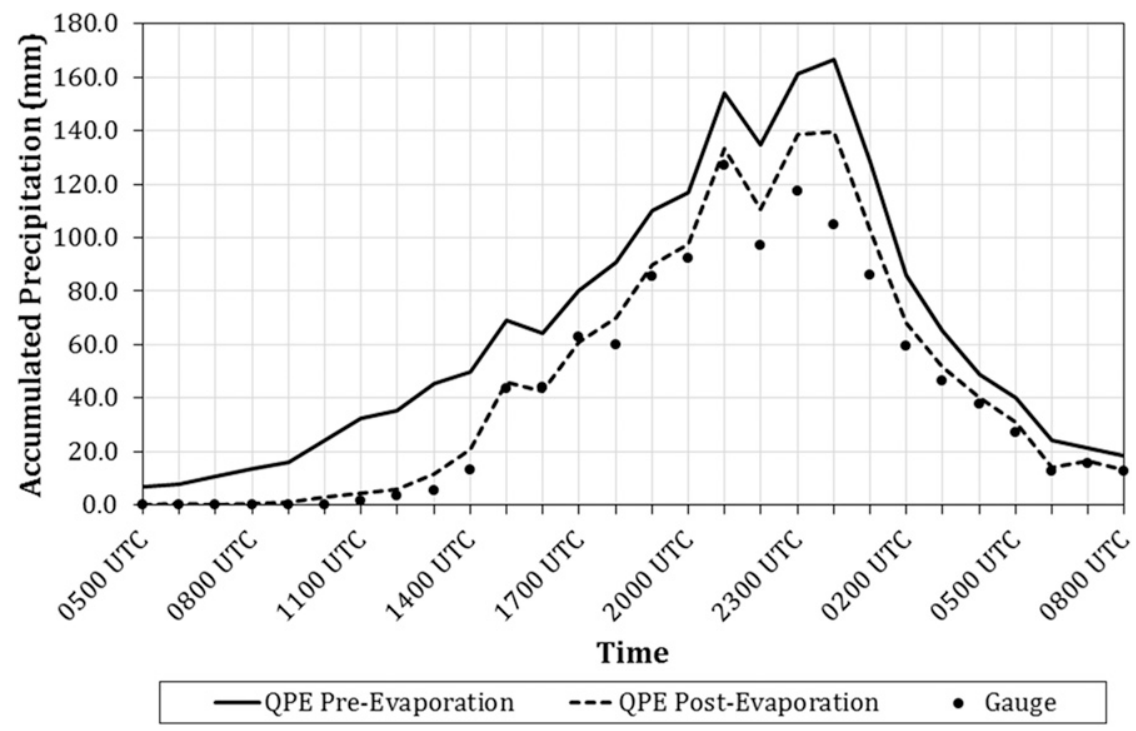

FIG. 5. Accumulated hourly gauge observations (points) along with accumulated hourly precipitation for MRMS radar-only QPE before evaporation correction (solid line) and after evaporation correction (dashed line) at grid cells containing gauge sites classified with pre-evaporation correction observations as nonzero passing values and false zero during event 1 .

precipitation (Martinaitis et al. 2015). This is discussed further in section $4 \mathrm{c}$.

\section{b. Desert southwest rain event: 20-21 September 2016}

Midlevel moisture was transported northeastward across the southwestern CONUS from the combination of Tropical Cyclone (TC) Paine centered approximately $450 \mathrm{~km}$ west-southwest of Cabo San Lazaro, Mexico, and a large ridge located over northwest Mexico at the start of the event 1 study period. TC Paine rapidly decreased in intensity from a hurricane at 0300 UTC 20 September to a remnant low at 0300 UTC 21 September. For a complete discussion of TC Paine, see Blake (2016). Moisture from TC Paine spread over Southern California into Arizona and northwest New Mexico during the case study period. Atmospheric profiles portrayed a very dry environment across Arizona and New Mexico, with increased moisture moving into the western part of the domain in response to TC Paine (Fig. 3).

The evaporation correction algorithm significantly reduced the forward flank of the precipitation coverage into northern Arizona during the start of the analysis period (Figs. 4a,b). Greater precipitation coverage was retained as the $3 \mathrm{D}$ atmospheric profile became more saturated across Arizona (Figs. 4c-f), while isolated convection developed across southern Arizona and New Mexico by 2300 UTC 20 September (Figs. 4g,h). The evaporation correction scheme also effectively removed virga sampled at farther distances from radar. The $\mathrm{Al}-$ buquerque, New Mexico, WSR-88D radar (KABX) sampled precipitation in its lowest available datum to the west and north at a range of at least $90 \mathrm{~km}$ and an altitude of $>2.0 \mathrm{~km}$ AGL (e.g., Fig. 4g). The evaporation correction scheme correctly removed this precipitation (e.g., Fig. 4h), since gauge observations in the region recorded zero precipitation.

Accumulated precipitation values at precipitation gauge sites across the study domain showed a distinct overestimation of the original MRMS radar-only QPE for all hours (Fig. 5). The postevaporation correction of the MRMS radar-only QPE was better correlated with the referenced gauge observations. MRMS radar-only precipitation estimates were mitigated at gauge sites reporting no precipitation, and the overestimation of radar precipitation compared to nonzero gauge observations was reduced. The period from 2200 UTC 20 September to 0100 UTC 21 September still resulted in an overall significant overestimation of evaporation-corrected radar QPE that coincided with the peak precipitation accumulation.

Removal of the initial false precipitation plume across Arizona from 0500 to 1500 UTC 20 September resulted in the greatest performance improvement for all statistical measures (Fig. 6). The average ME for this period was reduced by $91.0 \%$ from -0.517 to $-0.047 \mathrm{~mm}$, and the average MAE was reduced by $86.1 \%$ from 0.526 to $0.071 \mathrm{~mm}$. Available FB and CC values from 0900 to 1500 
a)

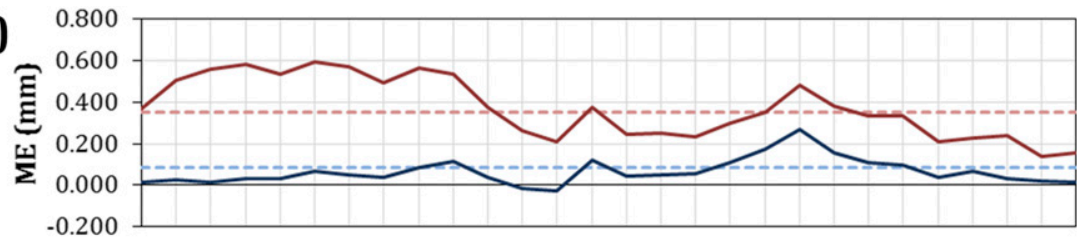

b)

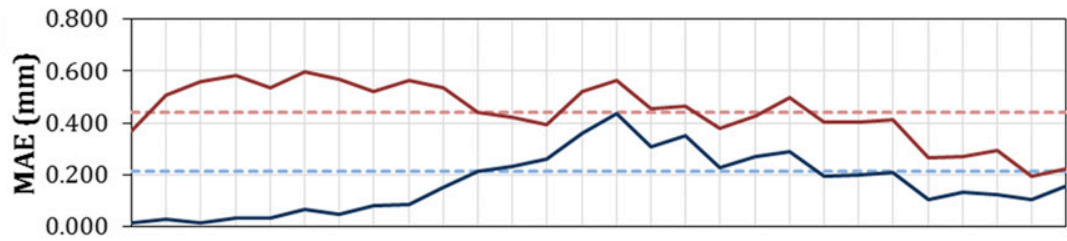

c)

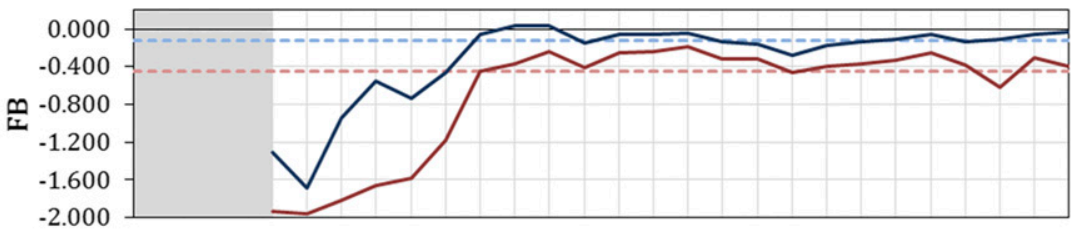

d)
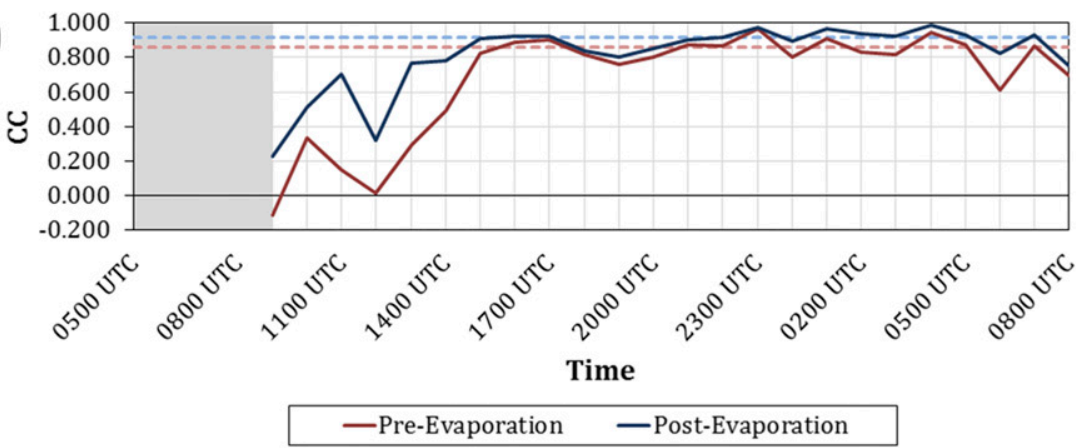

FIG. 6. Hourly (a) ME, (b) MAE, (c) FB, and (d) CC for MRMS radar-only QPE performance pre-evaporation correction (solid red line) and postevaporation correction (solid blue line) for event 1 . The event average pre-evaporation (dashed red line) and postevaporation (dashed blue line) values are also plotted. Statistical values for FB and CC from 0500 to 0800 UTC 20 Sep could not be calculated since no precipitation was accumulated within any gauges.

UTC were improved by $45.7 \%$ and $110.9 \%$, respectively. Changes in all statistical measures were not as significant when the accumulated precipitation over the domain per gauge observations increased, yet improvements were shown for every hour through the rest of the event (Fig. 6).

The pre- and postevaporation-corrected radar-only QPE for locations where passing $G$ and $R>0$ gauge observations also showed a decrease of the precipitation overestimation bias (Fig. 7). The overall MBR for areas receiving measurable precipitation at the surface was reduced from 1.114 to 0.978 . The greatest changes in the MBR were for gauge values $\leq 0.76 \mathrm{~mm}$ ( $0.03 \mathrm{in}$.), and the average radar QPE values after evaporation correction reduced the overestimation bias and approached an MBR of 1.00 with gauge values $\leq 1.27 \mathrm{~mm}$ (0.05 in.;
Table 14). Postevaporation radar QPE values showed an underestimation bias when compared to gauge observations $\geq 1.52 \mathrm{~mm}$ (0.06 in.), but changes in the MBR were less significant as hourly gauge accumulations increased. This is likely a result of the limited application of evaporation on more intense rates per Eq. (15).

The evaporative correction of radar QPE was also reflected in how gauge observations were quality controlled. The majority of gauge sites from 0500 to 1600 UTC 20 September were classified as false zero observations before evaporation correction, followed by an increase of surface precipitation coverage and passing nonzero observations (Fig. 8). The removal of false zero gauge observations and their reclassification to passing 


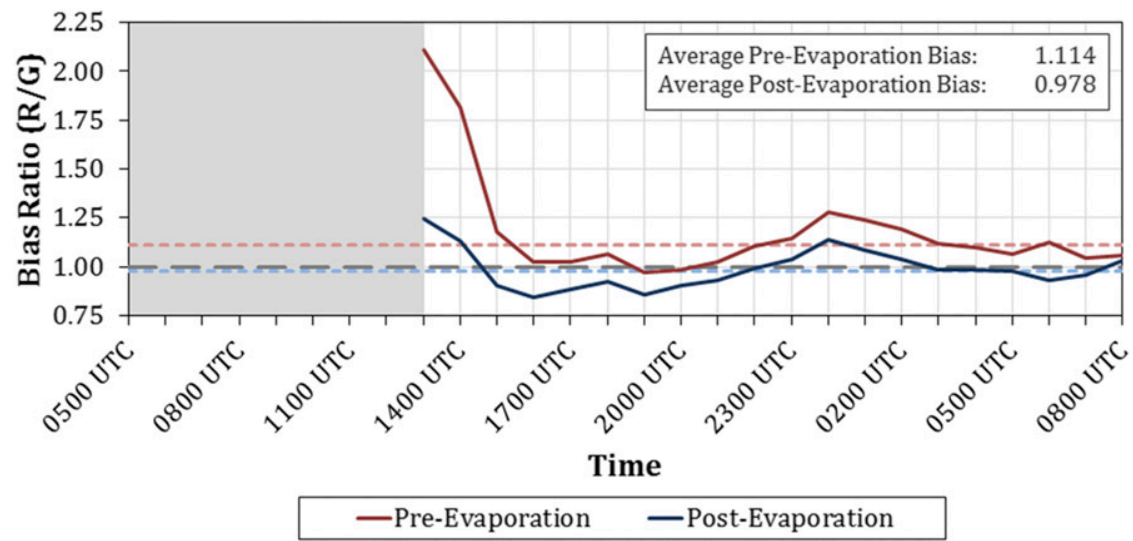

FIG. 7. Hourly MBR of MRMS radar-only QPE pre-evaporation correction (solid red line) and postevaporation correction (solid blue line) compared to gauge observations classified as passing with nonzero values for hours that contained a minimum of 10 observations during event 1 . Hours with less than 10 gauge observations classified as passing with nonzero values are shaded in gray. The average pre-evaporation MBR (dashed red line) and the postevaporation MBR (dashed blue line) are also plotted. The dark gray dashed line represents a MBR of 1.00, which states that the accumulated radar QPE is equal to the accumulated gauge observations. MBR values $>1.00$ represent an overestimation of precipitation by the radar-only QPE. MBR values $<1.00$ represent an underestimation.

$G$ and $R=0$ observations was greatest when most precipitation was not reaching the surface. Approximately $85.0 \%$ of false zero observations were reclassified from 0500 to 1100 UTC 20 September, while only $38.1 \%$ of false zero observations were reclassified when the greatest accumulation of surface precipitation occurred from 2000 UTC 20 September to 0100 UTC 21 September (Fig. 9). The number of gauge observations per hour classified as false precipitation increased with greater precipitation coverage, but the number of false precipitation observations per hour did not significantly change after evaporation correction (see event 1 in Table 11). This denotes that the scheme was removing very little true surface precipitation.

\section{c. Great Lakes snow event: 30 January-1 February 2017}

A low pressure system located over southern Manitoba on 30 January 2017 tracked southeast and east across the Great Lakes, which resulted in light snowfall across this region during event 7. A second low pressure system off the New Jersey coast also provided light snow across the mid-Atlantic region on 30 January. Increased reflectivity returns on radar but no measured surface precipitation occurred north of a zonal-oriented frontal boundary from West Virginia to Nebraska on 1 February. Atmospheric profiles portrayed a relatively moist atmosphere near the primary low pressure system with reduced relative humidity values ahead of the system
(Fig. 10). The atmosphere was also less humid above $1000 \mathrm{~m}$ AGL near the aforementioned frontal boundary, per the observed relative humidity profile from Lincoln, Illinois (Fig. 10b).

The evaporation correction algorithm reduced some areal coverage of snow across the Great Lakes and midAtlantic region throughout the study period, and there was a more substantial removal of false surface precipitation near the frontal boundary toward the end of the study period (Fig. 11). A notable observation from the false precipitation north of the frontal boundary and the removal of precipitation coverage was the shape of precipitation with respect to the location of WSR-88D

TABLE 14. The change in the MBR between the hourly MRMS radar-only QPE before and after evaporation correction and the gauge observations classified as passing (nonzero) stratified by different gauge values during event 1 . Listed is also the sample size $N$.

\begin{tabular}{cccr}
\hline \hline & \multicolumn{3}{c}{ MBR } \\
\cline { 2 - 3 } Gauge value $(\mathrm{mm})$ & Pre-evaporation & Postevaporation & $N$ \\
\hline 0.25 & 2.143 & 1.450 & 229 \\
0.51 & 1.596 & 1.242 & 130 \\
0.76 & 1.324 & 1.157 & 93 \\
1.02 & 1.179 & 1.015 & 189 \\
1.27 & 1.194 & 1.041 & 72 \\
$1.52-1.78$ & 1.060 & 0.931 & 60 \\
$2.03-2.54$ & 1.005 & 0.919 & 89 \\
$2.79-5.08$ & 0.875 & 0.847 & 80 \\
$>5.08$ & 0.842 & 0.815 & 12 \\
\hline
\end{tabular}




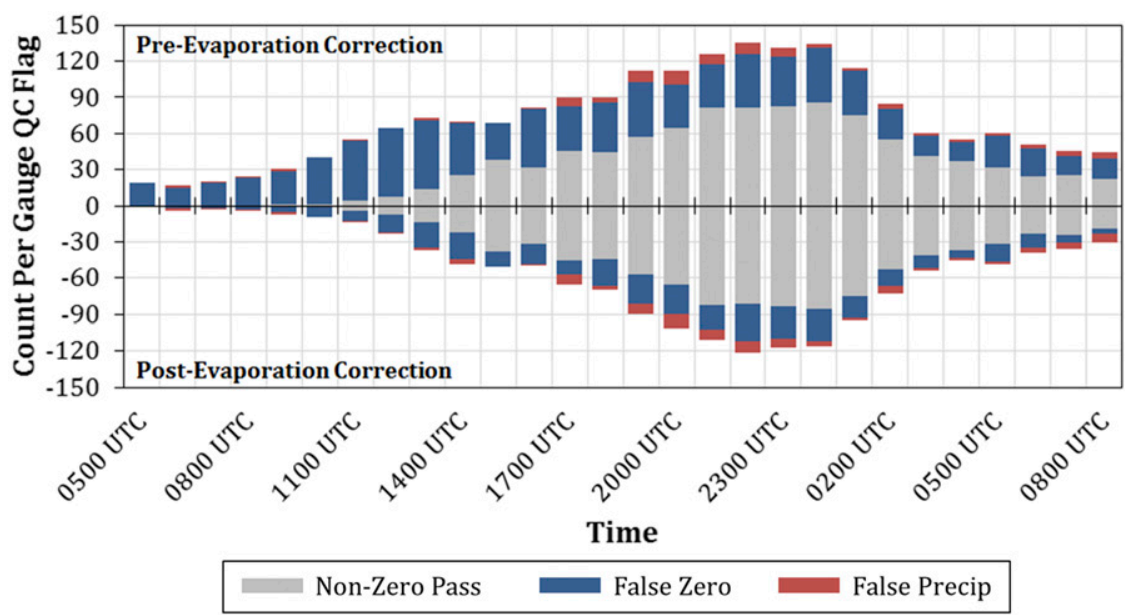

FIG. 8. Comparison of the number of gauge observations per relevant gauge QC classification (top half) pre-evaporation and (bottom half) postevaporation correction for each hour during event 1.

radars. The reflectivity values detected by radar and its subsequent generation of nonzero QPE values were located between radar sites where the lowest available datum detected precipitation well above the surface [e.g., around the Indianapolis, Indiana (KIND); Lincoln, Illinois (KILX); and St. Louis, Missouri (KLSX) radars in Fig. 11g]. This resulted in circular-style features of QPE values around these WSR-88D radars. The evaporation scheme effectively removed most of this precipitation coverage (Fig. 11h).

Accumulated precipitation values at precipitation gauge sites showed an apparently distinct overestimation of the pre-evaporation MRMS radar-only QPE during the entire study period (Fig. 12). Application of the evaporation correction scheme reduced some of the overestimation bias of the radar QPE; however, it is unknown what percentage of the precipitation overestimation was based on false surface precipitation or from the inability of gauge sites to properly measure the liquid equivalent of frozen precipitation reaching the surface.

The winter precipitation challenges with gauge observations were are also reflected in the hourly statistical analyses (Fig. 13). Average changes in ME (39.0\%) and MAE $(31.7 \%)$ prior to 0200 UTC 1 February were less than the improvements seen in rain events. Approximately $82.8 \%$ of the gauge observations were flagged as

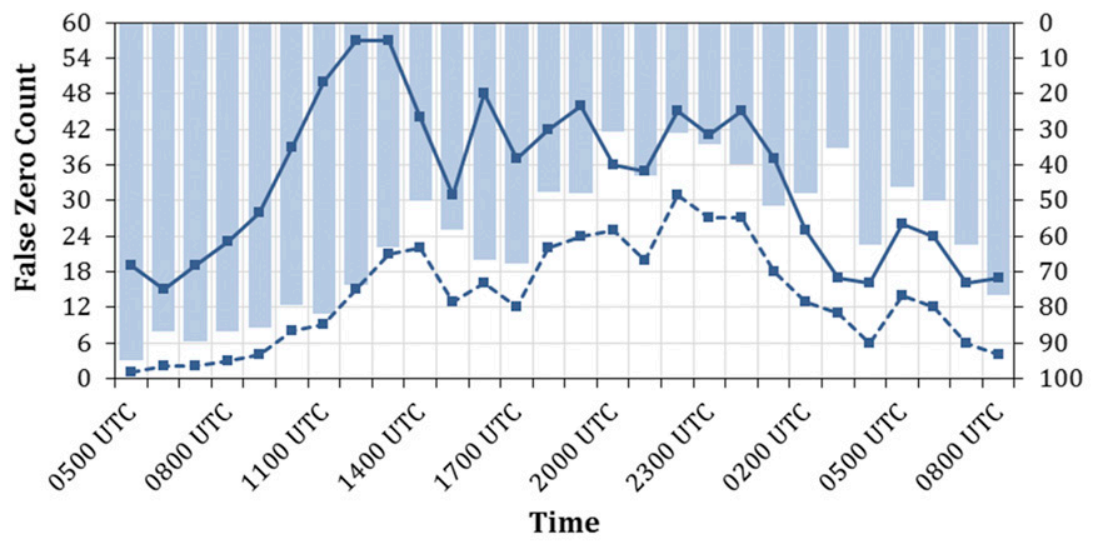

- Percent Difference $\rightarrow$-Pre-Evaporation Correction $\quad-m-$ Post-Evaporation Correction

FIG. 9. The number of gauge observations labeled as false zero pre-evaporation correction (solid blue line) and postevaporation correction (dashed blue line) along with the percent reduction of the number of false zero gauge observations (bar graph) with the application of the evaporation correction scheme for event 1 . 


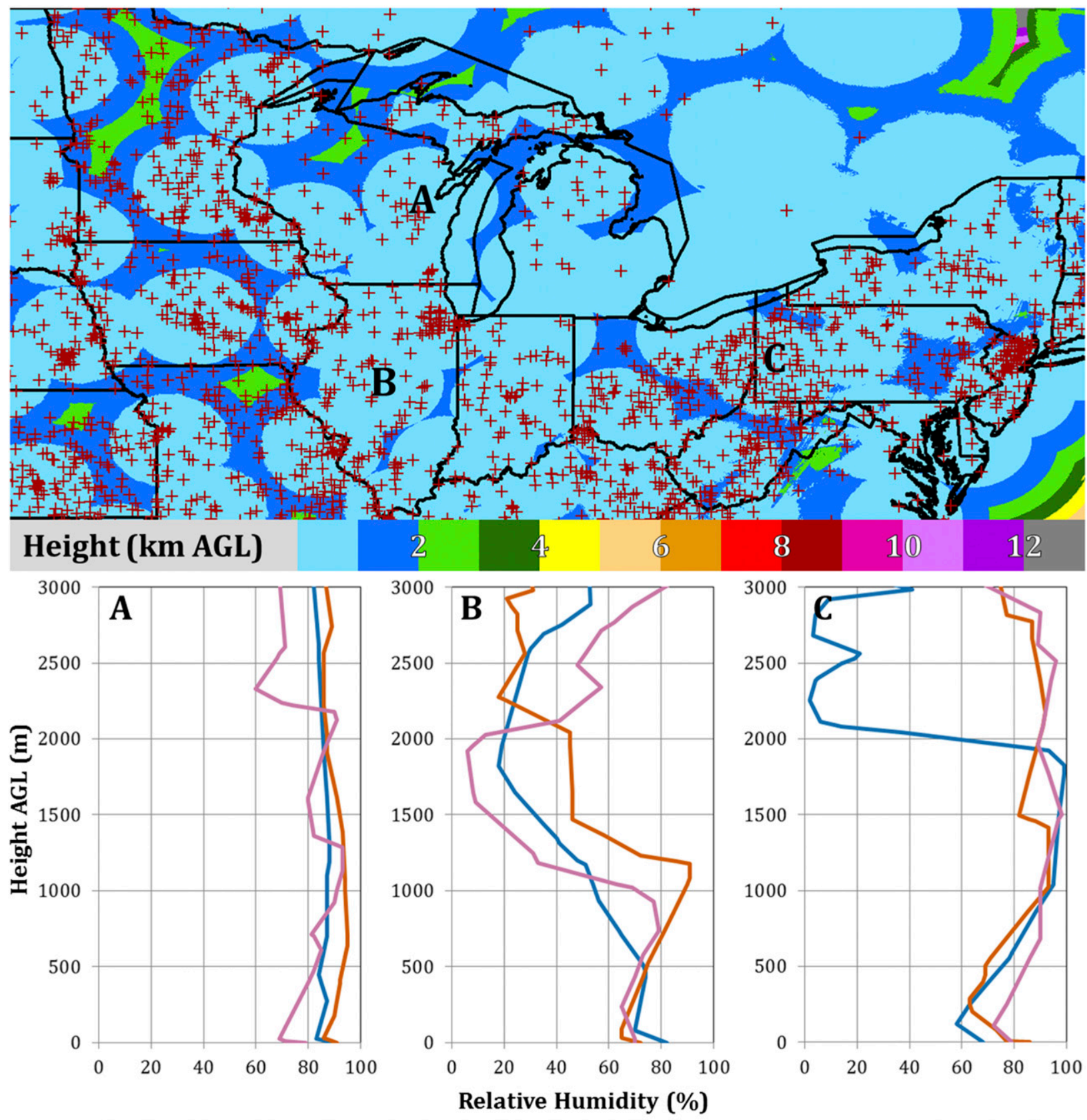

—0000 UTC 31 January 2017 —1200 UTC 31 January 2017 —0000 UTC 1 February 2017

FIG. 10. Height of lowest available radar data from SHSR ( $\mathrm{km}$ AGL) and gauge locations (red + symbols) for the domain of event 7 with observed relative humidity profiles for (a) Green Bay, Wisconsin; b) Lincoln, Illinois; and (c) Pittsburgh, Pennsylvania at 0000 UTC 31 Jan 2017 (blue), 1200 UTC 31 Jan 2017 (orange), and 0000 UTC 1 Feb 2017 (purple) to a height of $3000 \mathrm{~m}$ AGL.

frozen impacts; thus, it is unknown if the gauges reported no precipitation due to winter precipitation impacts or if no precipitation existed at the surface. The improvements in ME and MAE then increased to $60.3 \%$ and $55.7 \%$, respectively, from 0200 to 1000 UTC 1
February when only $39.0 \%$ of gauge observations were defined by frozen impacts during this period. Improvements in FB values were also not as significant as the improvement identified during rainfall events. Only two hours had FB values within the adequate performance 


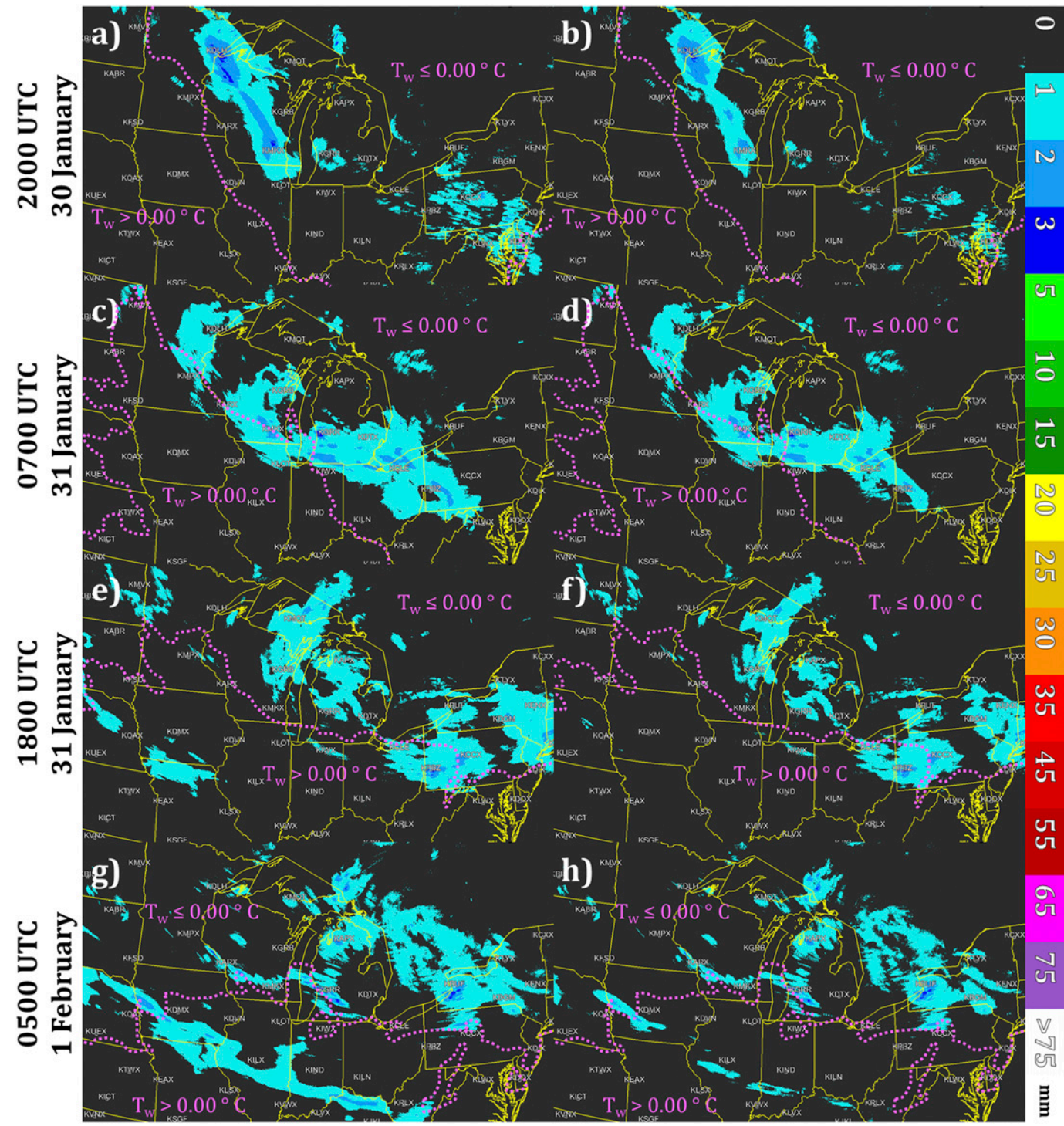

Pre-Evaporation Correction

Post-Evaporation Correction

FIG. 11. Hourly MRMS radar-only QPE accumulations (left) before and (right) after pre-evaporation correction during event 7 for the following times: (a),(b) 2000 UTC 30 Jan; (c),(d) 0700 UTC 31 Jan; (e),(f) 1800 UTC 31 Jan; and (g),(h) 0500 UTC $1 \mathrm{Feb}$. The hourly RAP model $T_{w}=0.00^{\circ} \mathrm{C}$ (pink dashed contour) is plotted to help delineate regions likely experiencing rain or snow during the event.

range of $-0.5 \leq \mathrm{FB} \leq+0.5$. A distinct oscillatory pattern in $\mathrm{CC}$ value improvements was observed during the event (Fig. 13d). An average CC increase of 0.155 was calculated for the hours between 0100 and 1000 UTC, while CC only increased by an average of 0.021 during the hours of peak diurnal heating from 1500 to 2100 UTC

The radar-only QPE for gauge observations classified as passing with nonzero values had a slight underestimation bias of 0.978 that increased to 0.914 with the application of the evaporation correction scheme (Fig. 14). The average change in the MBR was $6.5 \%$, and 18 of the 49 hours had a reduction in the MBR of $<5.0 \%$; thus, the overall increase in the underestimation bias was limited. Postevaporation radar QPE values still overestimated for locations that recorded hourly liquid equivalent gauge observations of $0.25 \mathrm{~mm}$ ( $0.01 \mathrm{in}$.), but underestimated for all other hourly gauge accumulations (Table 15). Greater underestimation bias ratios existed with greater hourly gauge values. It should be noted 


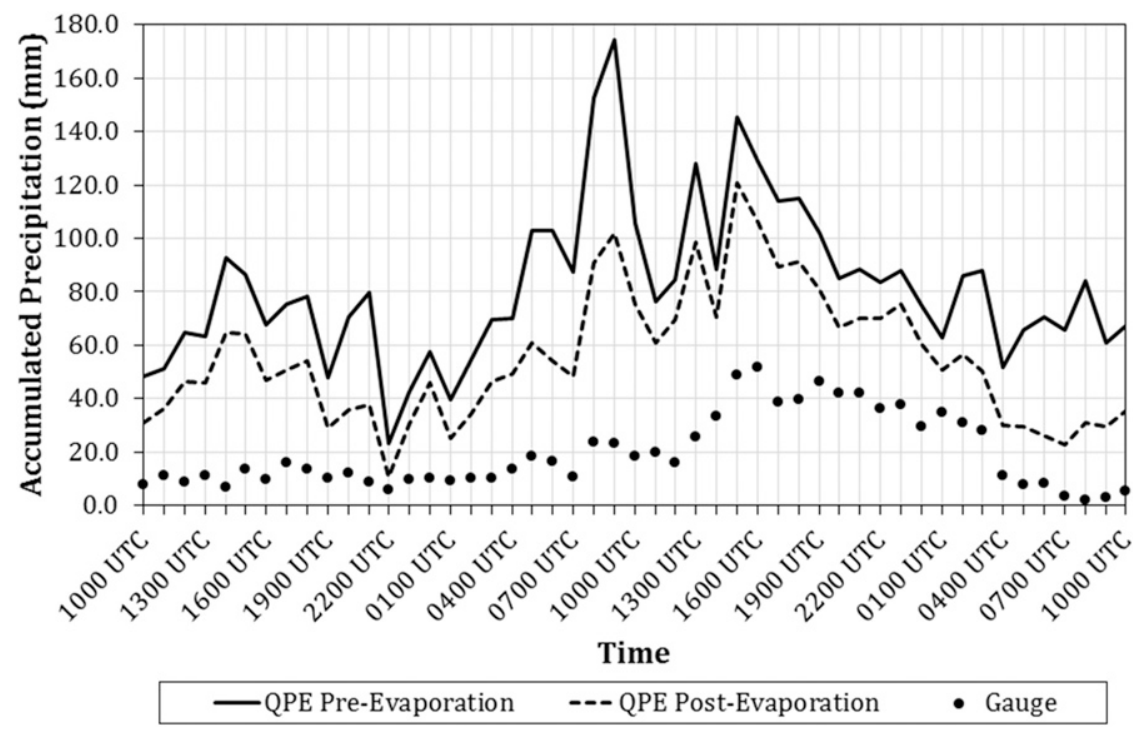

FIG. 12. As in Fig. 5, but at gauge sites classified pre-evaporation correction as passing for nonzero values, false zero, and frozen impacts during event 7.

that the strict outlier threshold $\mathrm{WR}_{\text {min }}$ would curtail the portrayal of overall potential overestimation biases by preventing the influence of partial winter precipitation impacts on gauge observations.

The majority of all hourly gauges were classified as false zero observations during the event (Fig. 15). The lack of nonzero gauge observations can be attributed to the potentially large quantity of automated gauges incapable of measuring the liquid equivalent of frozen precipitation. All but one hour before 1000 UTC 31 January saw at least a 30\% reduction in gauges classified as frozen impacts with an average reduction of $40.7 \%$ (Fig. 16a). The period from 1000 UTC 31 January to 0100 UTC February had a $18.1 \%$ reduction in frozen impacts classifications, followed by a $42.4 \% \mathrm{~h}^{-1}$ removal rate as more dry air was depicted in the modeled atmosphere. The number of false zero observations was minimal until 1500 UTC 31 January. An average of $27.4 \%$ false zero observations was removed before 0200 UTC 1 February. This increased to a $67.0 \% \mathrm{~h}^{-1}$ reduction from 0200 to 1000 UTC 1 February. This larger reduction starting at 0200 UTC 1 February is comparable to the reduction of false zero gauge observations seen in rain-only events (Fig. 16b).

Gauge observations labeled as false precipitation were more pronounced in this case compared to the other evaluated events; moreover, the number of false precipitation gauge observations increased by $11.6 \%$ after evaporation correction. Peaks in gauge observations classified as false precipitation occurred daily between 1500 and 2100 UTC, which matched the findings by Martinaitis et al. (2015) regarding thawing winter precipitation during peak diurnal heating. It is plausible that the impacts of postevent thawing on gauge observations during diurnal heating hindered some of the statistical improvements during the course of the event (Table 16), which explains the oscillatory pattern shown in hourly CC values (Fig. 13d).

Radar-detected precipitation simultaneously occurring at a gauge site experiencing postevent thaw can introduce an inaccurate bias correction to radar-derived QPE (Martinaitis et al. 2015). The comparison of a gauge experiencing postevent thaw collocated with radar-detected precipitation not reaching the surface can incorrectly retain the nonzero gauge observation by passing gauge QC, and thus, the gauge can be utilized in other MRMS products and verification. The removal of false surface precipitation through the evaporation correction scheme allowed for the identification and dismissal of more gauges impacted by postevent thaw. Potentially correct nonzero gauge observations could have also been discarded during this event, yet it is difficult to quantify what percentage of false precipitation observations were based on postevent thaw or from removing accurate precipitation recorded at the surface.

\section{Summary and future work}

Precipitation estimated by radar is generally not equivalent to the amount of precipitation measured at the surface. One significant contributor to this difference is evaporation. Numerous studies have applied 
a)

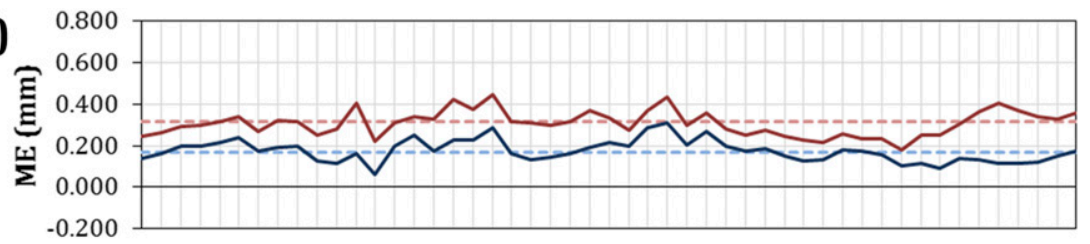

b)

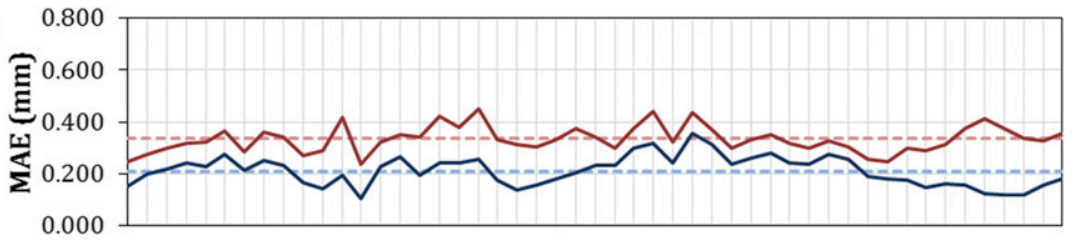

c)

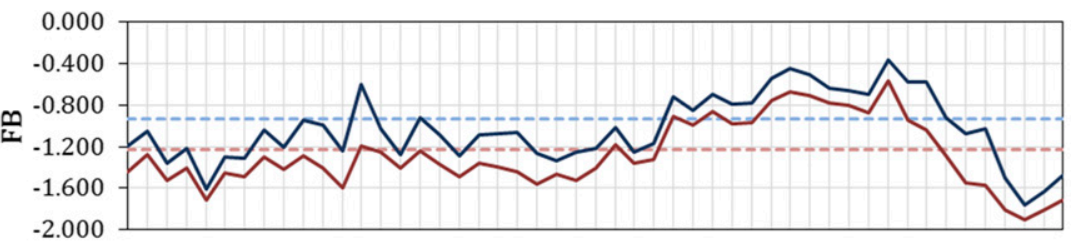

d)
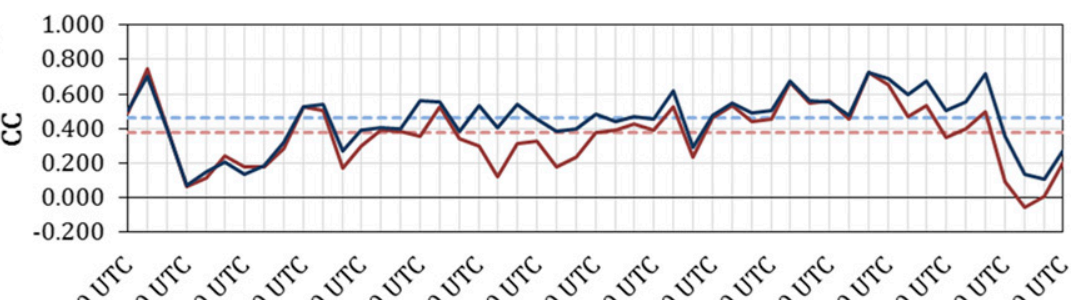

Time

-Pre-Evaporation -Post-Evaporation

FIG. 13. As in Fig. 6, but for event 7.

evaporation correction techniques to either onedimensional rainshafts or large-scale numerical models; however, the majority of techniques are computationally inefficient for real-time applications. This study evaluated the application of a simplified evaporation correction scheme within the high spatiotemporal resolution real-time MRMS system to improve radar-derived QPE coverage and magnitude. The

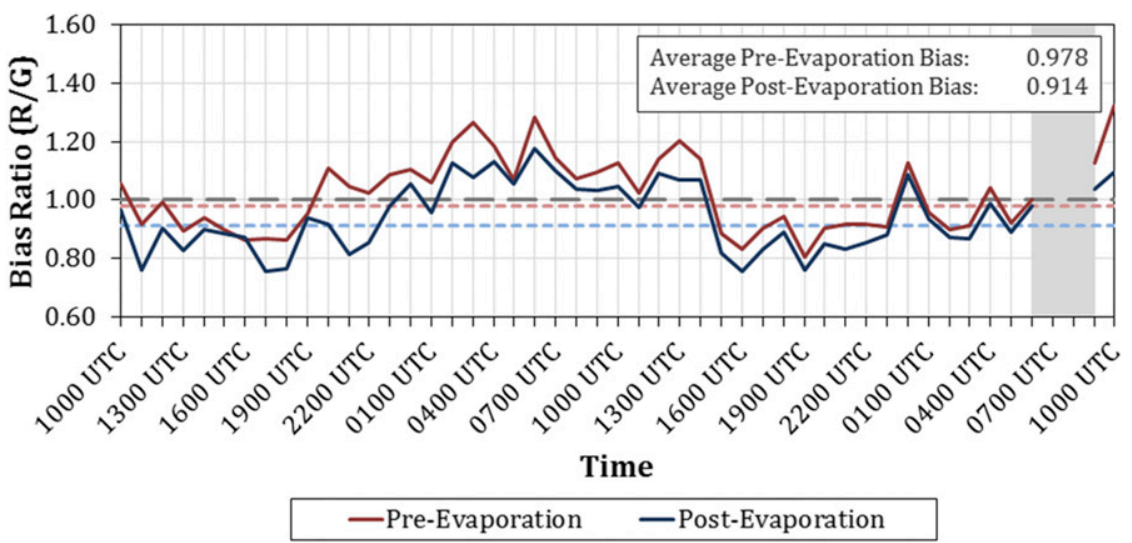

FIG. 14. As in Fig. 7, but for event 7. 
TABle 15. As in Table 14, but for event 7.

\begin{tabular}{cccc}
\hline & \multicolumn{3}{c}{ MBR } \\
\cline { 2 - 3 } Gauge value $(\mathrm{mm})$ & Pre-evaporation & Postevaporation & $N$ \\
\hline 0.25 & 1.287 & 1.228 & 942 \\
0.51 & 1.000 & 0.924 & 351 \\
0.76 & 0.965 & 0.904 & 133 \\
1.02 & 0.814 & 0.772 & 199 \\
1.27 & 0.778 & 0.722 & 42 \\
$1.52-1.78$ & 0.878 & 0.828 & 42 \\
$2.03-2.54$ & 0.578 & 0.535 & 28 \\
$2.79-5.08$ & 0.736 & 0.692 & 4 \\
$>5.08$ & - & - & - \\
\hline
\end{tabular}

implementation of this scheme yielded the following conclusions:

1) ME values of hourly radar-derived QPE compared to gauge observations were reduced by an average of $64.8 \%$ for rain events and $45.5 \%$ for snow events. Notable improvements for MAE and CC were also observed for all analyzed events. Adequate performance values for FB were shown for the rain events; however, minimal improvement was noted for the snow cases. The smaller improvements in statistical measures for the snow events can be attributed to the limitations of automated gauge sites in winter precipitation.

2) MBR values for when the radar and gauges were reporting nonzero values had the greatest overestimation with the smallest gauge accumulations (i.e., $0.25 \mathrm{~mm}$ ) with underestimation of the radar QPE at greater gauge totals. The evaporation correction scheme significantly reduced the large overestimation biases of radar-derived QPE values versus the lesser gauge values while only slightly increasing the underestimation biases with greater gauge values.

3) The removal of false surface precipitation was assessed through a gauge QC algorithm and gaugeradar comparisons. An average of $52.1 \%$ gauges that were considered as false observations were reclassified as passing $G$ and $R=0$ observations during rain events when using evaporation-corrected radar-only QPE. This reclassification was reduced to $38.2 \%$ for snow; however, quantifying the exact impacts of evaporation for winter precipitation events were challenging given the limitations automated gauge stations have with measuring liquid equivalent values. Some caution should be taken with these results, since it is unknown how much true surface winter precipitation occurred at the surface from a gauge perspective.

4) The evaporation correction scheme removed little real surface precipitation during rain events. More nonzero passing gauge observations were marked as incorrect during snowfall events; however, some nonzero gauge observations could be attributed to diurnal postevent thawing.

5) The computation efficiency of the algorithm produced little additional product latency. The evaporation correction algorithm applied to the MRMS precipitation rates is completed in $6-7 \mathrm{~s}$, which allows for the generation of the corrected precipitation rate and accumulated QPE products to still occur within the 2-min temporal resolution of MRMS.

The equations developed by Gregory (1995) were applicable to the MRMS system, since non-dual-polarization

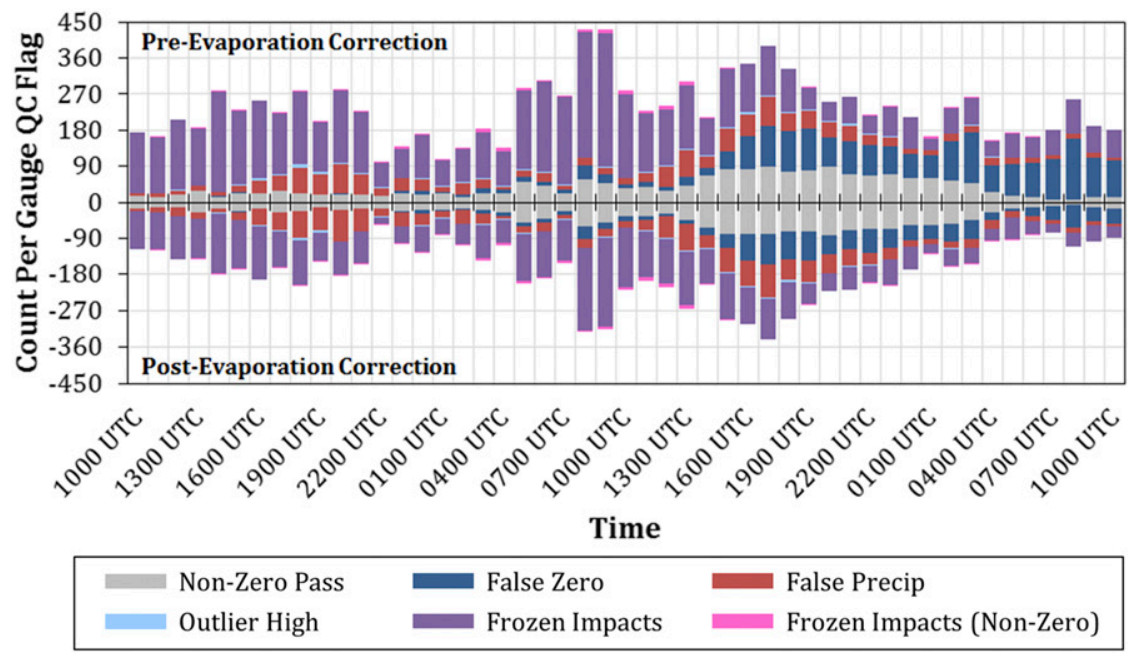

FIG. 15. As in Fig. 8, but for event 7. 


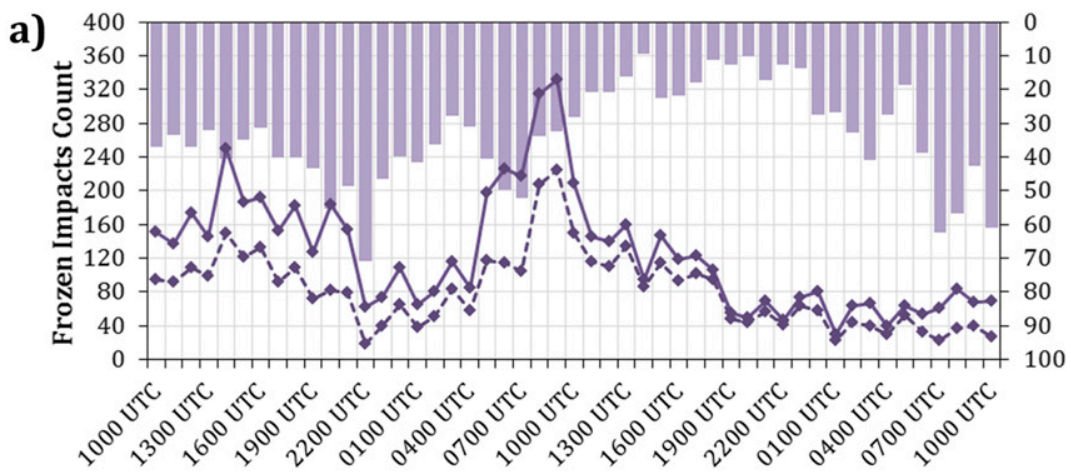

b)

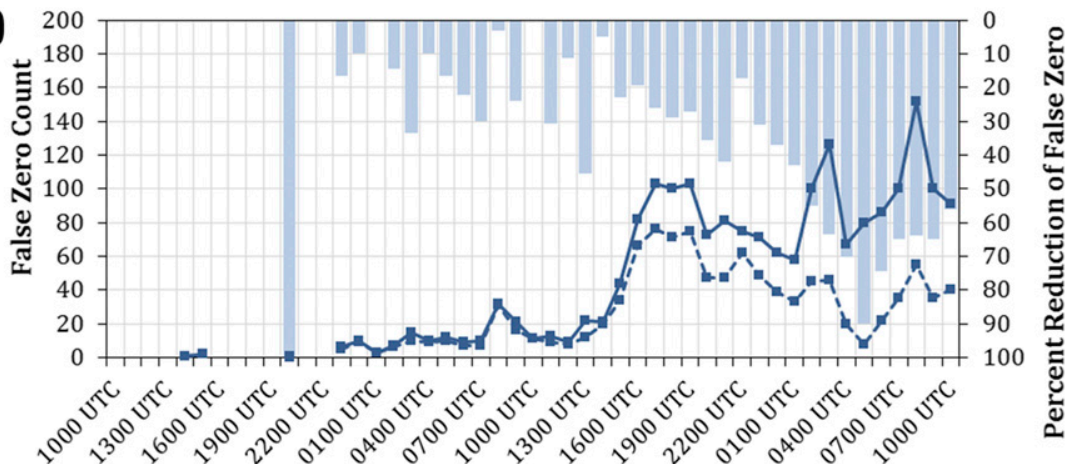

Time

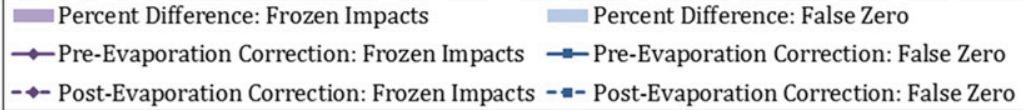

FIG. 16. The number of gauge observations labeled as (a) frozen impacts (purple) and (b) false zero (blue) pre-evaporation correction (solid line) and postevaporation correction (dashed line) along with the percent reduction of the number of gauge observations labeled for each QC classification (bar graph) with the application of the evaporation correction scheme for event 7.

radars are also utilized across the domain; however, more recent studies have shown that incorporating dual-polarization variables, such as $Z_{\mathrm{DR}}$, can improve the treatment of evaporation on falling hydrometeors. Future studies regarding the challenges of accounting for changes in $Z_{\mathrm{DR}}$ for hydrometeors above and passing through the melting layer, as well as the treatment of evaporation in the melting layer, could also improve evaporation techniques using dual-polarization data. Additional future work for implementing a dual-polarization-based evaporation correction scheme would require mosaicked, dualpolarization variables and a blending of schemes to provide varying evaporation correction algorithms

TABLE 16. Average improvements of ME ( $\mathrm{mm})$, MAE $(\mathrm{mm}), \mathrm{FB}$, and $\mathrm{CC}$ using the evaporation correction scheme for the different 0100-1000 UTC and 1500-2100 UTC time periods during the event.

\begin{tabular}{|c|c|c|c|c|}
\hline \multirow[b]{3}{*}{ Statistical measures } & \multicolumn{4}{|c|}{ Improvement in QPE using evaporation } \\
\hline & \multirow{2}{*}{$\frac{30 \text { January }}{1500-2100 \text { UTC }}$} & \multicolumn{2}{|c|}{31 January } & \multirow{2}{*}{$\frac{1 \text { February }}{0100-1000 \text { UTC }}$} \\
\hline & & 0100-1000 UTC & 1500-2100 UTC & \\
\hline $\mathrm{ME}(\mathrm{mm})$ & -0.141 & -0.159 & -0.088 & -0.188 \\
\hline $\operatorname{MAE}(\mathrm{mm})$ & -0.121 & -0.157 & -0.069 & -0.181 \\
\hline FB & +0.277 & +0.268 & +0.191 & +0.329 \\
\hline $\mathrm{CC}$ & +0.013 & +0.163 & +0.029 & +0.146 \\
\hline
\end{tabular}


based on radar technology. Advancement in computation speed will facilitate the use of higher spatiotemporal model data to provide more accurate depictions of the $3 \mathrm{D}$ atmosphere when correcting instantaneous precipitation rates as well as additional radar inputs from dualpolarization variables.

Acknowledgments. The authors thank the anonymous reviewers for their time and feedback with this manuscript. The authors also thank Alexander Ryzhkov (NSSL) for his insight on the subject matter and his review of this study and Ami Arthur (CIMMS/NSSL) for her assistance with data visualizations. Funding was provided by NOAA/Office of Oceanic and Atmospheric Research under NOAA-University of Oklahoma Cooperative Agreement NA11OAR4320072, U.S. Department of Commerce, as well as the NWS Radar Operations Center technology transfer memorandum of understanding.

\section{REFERENCES}

Benjamin, S. G., and Coauthors, 2016: A North American hourly assimilation and model forecast cycle: The Rapid Refresh. Mon. Wea. Rev., 144, 1669-1694, https://doi.org/10.1175/ MWR-D-15-0242.1.

Blake, E. S., 2016: Hurricane Paine. NOAA/National Hurricane Center Tropical Cyclone Rep., 13 pp., http://www.nhc.noaa.gov/ data/tcr/EP172016_Paine.pdf.

Bringi, V. N., M. A. Rico-Ramirez, and M. Thurai, 2011: Rainfall estimation with an operational polarimetric C-band radar in the United Kingdom: Comparison with a gauge network and error analysis. J. Hydrometeor., 12, 935-954, https://doi.org/ 10.1175/JHM-D-10-05013.1.

Clough, S. A., and R. A. A. Franks, 1991: The evaporation of frontal and other stratiform precipitation. Quart. J. Roy. Meteor. Soc., 117, 1057-1080, https://doi.org/10.1002/ qj. 49711750109.

Cocks, S. B., J. Zhang, S. M. Martinaitis, Y. Qi, B. Kaney, and K. Howard, 2017: MRMS QPE performance east of the Rockies during the 2014 warm season. J. Hydrometeor., 18, 761-775, https://doi.org/10.1175/JHM-D-16-0179.1.

Comstock, K. K., R. Wood, S. E. Yuter, and C. S. Bretherton, 2004: Reflectivity and rain rate in and below drizzling stratocumulus. Quart. J. Roy. Meteor. Soc., 130, 2891-2918, https://doi.org/ 10.1256/qj.03.187.

Cui, B., Z. Toth, Y. Zhu, and D. Hou, 2012: Bias correction for global ensemble forecast. Wea. Forecasting, 27, 396-410, https://doi.org/10.1175/WAF-D-11-00011.1.

Feingold, G., 1993: Parameterization of evaporation of rainfall for use in general circulation models. J. Atmos. Sci., 50, 3454-3467, https://doi.org/10.1175/1520-0469(1993)050<3454: POTEOR $>2.0 . \mathrm{CO} ; 2$.

Goodrich, D. C., J.-M. Faures, D. A. Woolhiser, L. J. Lane, and S. Sorooshian, 1995: Measurement and analysis of small-scale convective storm rainfall variability. J. Hydrol., 173, 283-308, https://doi.org/10.1016/0022-1694(95)02703-R.

Gori, E. G., and J. Joss, 1980: Changes of shape of raindrop size distributions simultaneously observed along a mountain slope. J. Rech. Atmos., 14, 239-300.
Grams, H., J. Zhang, and K. Elmore, 2014: Automated identification of enhanced rainfall rates using the near-storm environment for radar precipitation estimates. J. Hydrometeor., 15, 1238-1254, https://doi.org/10.1175/JHM-D-13-042.1.

Gregory, D., 1995: A consistent treatment of the evaporation of rain and snow for use in large-scale models. Mon. Wea. Rev., 123, 2716-2732, https://doi.org/10.1175/1520-0493(1995)123<2716: ACTOTE $>2.0 . C O ; 2$.

Harrison, D. L., S. J. Driscoll, and M. Kitchen, 2000: Improving precipitation estimates from weather radar using quality control and correction techniques. Meteor. Appl., 7, 135-144, https://doi.org/10.1017/S1350482700001468.

Heymsfield, A. J., and L. J. Donner, 1990: A scheme for parameterizing ice water content in general circulation models. J. Atmos. Sci., 47, 1865-1877, https://doi.org/10.1175/ 1520-0469(1990)047<1865:ASFPIC >2.0.CO;2.

$\mathrm{Hu}, \mathrm{Z}$., and R. C. Srivastava, 1995: Evolution of raindrop size distribution by coalescence, breakup, and evaporation: Theory and observations. J. Atmos. Sci., 52, 1761-1783, https://doi.org/ 10.1175/1520-0469(1995)052<1761:EORSDB >2.0.CO;2.

Kalogiros, J., M. N. Anagnostou, E. A. Anagnostou, M. Montopoli, E. Picciotti, and F. S. Marzano, 2014: Evaluation of a new polarimetric algorithm for rain-path attenuation correction of $\mathrm{X}$-band radar observations against disdrometer. IEEE Trans. Geosci. Remote Sens., 52, 1369-1380, https://doi.org/10.1109/ TGRS.2013.2250979.

Kinzer, G. D., and R. Gunn, 1951: The evaporation, temperature and thermal relaxation-time of freely falling waterdrops. J. Meteor., 8, 71-83, https://doi.org/10.1175/ 1520-0469(1951)008<0071:TETATR >2.0.CO;2.

Krajewski, W. F., G. Villarini, and J. A. Smith, 2010: Radar-rainfall uncertainties: Where are we after thirty years of effort? Bull. Amer. Meteor. Soc., 91, 87-94, https://doi.org/10.1175/ 2009BAMS2747.1.

Kumjian, M. R., and A. V. Ryzhkov, 2010: The impact of evaporation on polarimetric characteristics or rain: Theoretical model and practical implications. J. Appl. Meteor. Climatol., 49, 1247-1267, https://doi.org/10.1175/2010JAMC2243.1.

Leary, C. A., and R. A. Houze Jr., 1979: Melting and evaporation of hydrometeors in precipitation from the anvil clouds of deep tropical convection. J. Atmos. Sci., 36, 669-679, https://doi.org/ 10.1175/1520-0469(1979)036<0669:MAEOHI >2.0.CO;2.

Levin, Z., G. Feingold, and S. Tzivion, 1991: The evolution of raindrop spectra: Comparisons between modeled and observed spectra along a mountain slope in Switzerland. J. Appl. Meteor., 30, 893-900, https://doi.org/10.1175/1520-0450(1991)030<0893: TEORSC $>2.0 . \mathrm{CO} ; 2$.

Li, X., and R. C. Srivastava, 2001: An analytical solution for raindrop evaporation and its application to radar rainfall measurements. J. Appl. Meteor., 40, 1607-1616, https://doi.org/ 10.1175/1520-0450(2001)040<1607:AASFRE > 2.0.CO;2.

List, R. E., 1951: Smithsonian Meteorological Tables. 6th ed. Smithsonian Institution, 527 pp.

Marshall, J. S., and W. M. Palmer, 1948: The distribution of raindrops with size. J. Meteor., 5, 165-166, https://doi.org/10.1175/ 1520-0469(1948)005<0165:TDORWS > 2.0.CO;2.

Martinaitis, S. M., S. B. Cocks, Y. Qi, B. T. Kaney, J. Zhang, and K. Howard, 2015: Understanding winter precipitation impacts on automated gauge observations within a real-time system. J. Hydrometeor., 16, 2345-2363, https://doi.org/ 10.1175/JHM-D-15-0020.1.

Penide, G., V. V. Kumar, A. Protat, and P. T. May, 2013: Statistics of drop size distribution parameters and rain rates for 
stratiform and convective precipitation during the North Australian wet season. Mon. Wea. Rev., 141, 3222-3237, https://doi.org/10.1175/MWR-D-12-00262.1.

Qi, Y., and J. Zhang, 2017: A physically based two-dimensional seamless reflectivity mosaic for radar QPE in the MRMS system. J. Hydrometeor., 18, 1327-1340, https://doi.org/ 10.1175/JHM-D-16-0197.1.

- — — , and P. Zhang, 2013a: A real-time automated convective and stratiform precipitation segregation algorithm in native radar coordinates. Quart. J. Roy. Meteor. Soc., 139, 2233-2240, https://doi.org/10.1002/qj.2095.

,,,--- and Q. Cao, 2013b: VPR correction of bright band effects in radar QPEs using polarimetric radar observations. J. Geophys. Res. Atmos., 118, 3627-3633, https://doi.org/ 10.1002/jgrd.50364.

—, S. Martinaitis, J. Zhang, and S. Cocks, 2016: A real-time automated quality control of hourly rain gauge data based on multiple sensors in MRMS system. J. Hydrometeor., 17, 16751691, https://doi.org/10.1175/JHM-D-15-0188.1.

Rasmussen, R., and Coauthors, 2012: How well are we measuring snow: The NOAA/FAA/NCAR winter precipitation test bed. Bull. Amer. Meteor. Soc., 93, 811-829, https://doi.org/10.1175/ BAMS-D-11-00052.1.

Rogers, R. R., 1971: The effect of variable target reflectivity on weather radar measurements. Quart. J. Roy. Meteor. Soc., 97, 154-167, https://doi.org/10.1002/qj.49709741203.

_ , and M. K. Yau, 1996: A Short Course in Cloud Physics. 3rd ed. Butterworth-Heinemann, 290 pp.

Rosenfeld, D., and Y. Mintz, 1988: Evaporation of rain falling from convective clouds as derived from radar measurements. J. Appl. Meteor., 27, 209-215, https://doi.org/10.1175/ 1520-0450(1988)027<0209:EORFFC > 2.0.CO;2.

- D. Atlas, and D. B. Wolff, 1992: Beamwidth effects on $Z-R$ relations and area-integrated rainfall. J. Appl. Meteor., 31, 454-464, https://doi.org/10.1175/1520-0450(1992)031<0454: BEOZRR $>2.0 . \mathrm{CO} ; 2$.

- D. B. Wolff, and D. Atlas, 1993: General probability-matched relations between radar reflectivity and rain rate. J. Appl. Meteor., 32, 50-72, https://doi.org/10.1175/1520-0450(1993)032<0050: GPMRBR $>2.0 . \mathrm{CO} ; 2$.

Schlesinger, M. E., J.-E. Oh, and D. Rosenfeld, 1988: A parameterization of evaporation of rainfall. Mon. Wea. Rev., 116, 1887-1895, https://doi.org/10.1175/1520-0493(1988)116<1887: APOTEO $>2.0 . \mathrm{CO} ; 2$

Smith, C. J., 1986: The reduction of errors caused by bright bands in quantitative rainfall measurements made using radar J. Atmos. Oceanic Technol., 3, 129-141, https://doi.org/ 10.1175/1520-0426(1986)003<0129:TROECB > 2.0.CO;2.

Smith, J. A., D. J. Seo, M. L. Baeck, and M. D. Hudlow, 1996: An intercomparison study of NEXRAD precipitation estimates. Water Resour. Res., 32, 2035-2046, https://doi.org/10.1029/96WR00270.

Steiner, M., J. A. Smith, S. J. Burges, C. V. Alonso, and R. W. Darden, 1999: Effect of bias adjustment and rain gauge data quality control on radar rainfall estimation. Water Resour. Res., 35, 2487-2503, https://doi.org/10.1029/1999WR900142.
Sundqvist, H., 1988: Parameterization of condensation and associated clouds in models for weather prediction and general circulation simulation. Physically Based Modelling and Simulation of Climate and Climate Change: Part 1, M. E. Schlesinger, Ed., NATO ASI Series, Vol. 243, Springer, 433-462, https://doi.org/10.1007/978-94-009-3041-4_10.

Tang, L., J. Zhang, C. Langston, J. Krause, K. Howard, and V. Lakshmanan, 2014: A physically based precipitationnonprecipitation radar echo classifier using polarimetric and environmental data in a real-time national system. Wea. Forecasting, 29, 1106-1119, https://doi.org/10.1175/ WAF-D-13-00072.1.

Thériault, J. M., R. Rasmussen, K. Ikeda, and S. Landolt, 2012: Dependence of snow gauge collection efficiency on snowflake characteristics. J. Appl. Meteor. Climatol., 51, 745-762, https:// doi.org/10.1175/JAMC-D-11-0116.1.

U.K. Meteorological Office, 1964: Aspirated Psychrometer Readings, Degrees Celsius. Part III, Hygrometric Tables, 2nd ed. H. M. Stationary Office, $90 \mathrm{pp}$.

Ulbrich, C. W., 1983: Natural variations in the analytical form of the raindrop size distribution. J. Climate Appl. Meteor., 22, 1764-1775, https://doi.org/10.1175/1520-0450(1983)022<1764: NVITAF $>2.0 . C O ; 2$.

Wilson, J. W., and E. A. Brandes, 1979: Radar measurements of rainfall: A summary. Bull. Amer. Meteor. Soc., 60 , 1048-1058, https://doi.org/10.1175/1520-0477(1979)060<1048: RMORS $>2.0 . C O ; 2$

Xie, X., R. Evaristo, S. Troemel, P. Saavedra, C. Simmer, and A. Ryzhkov, 2016: Radar observations of evaporation and implications for quantitative precipitation and cooling rate estimation. J. Atmos. Oceanic Technol., 33, 1779-1792, https:// doi.org/10.1175/JTECH-D-15-0244.1.

Young, C. B., B. R. Nelson, A. A. Bradley, J. A. Smith, C. D. Peters-Lidard, A. Kruger, and M. L. Baeck, 1999: An evaluation of NEXRAD precipitation estimates in complex terrain. J. Geophys. Res., 104, 19 691-19703, https://doi.org/10.1029/ 1999JD900123.

Zhang, J., and Y. Qi, 2010: A real-time algorithm for the correction of brightband effects in radar-derived QPE. J. Hydrometeor., 11, 1157-1171, https://doi.org/10.1175/2010JHM1201.1.

,$- \ldots$, D. Kingsmill, and K. Howard, 2012a: Radar-based quantitative precipitation estimation for the cool season in complex terrain: Case studies from the NOAA Hydrometeorological Testbed. J. Hydrometeor., 13, 1836-1854, https:// doi.org/10.1175/JHM-D-11-0145.1.

,$- \ldots$, K. Howard, C. Langston, and B. Kaney, 2012b: Radar quality index (RQI) - A combined measure of beam blockage and VPR effects in a national network. Weather Radar and Hydrology, R. J. Moore, S. J. Cole, and A. J. Illingworth, Eds., IAHS Publ. 351, 388-393.

, and Coauthors, 2016: Multi-Radar Multi-Sensor (MRMS) quantitative precipitation estimation: Initial operating capabilities. Bull. Amer. Meteor. Soc., 97, 621-637, https://doi.org/ 10.1175/BAMS-D-14-00174.1. 